\title{
Do Stock Analysts Influence Merger Completion? \\ An Examination of Post-Merger Announcement Recommendations
}

\author{
David A. Becher \\ Jonathan B. Cohn \\ Jennifer L. Juergens ${ }^{\dagger}$
}

May 2014

This paper investigates the effects of analyst recommendations issued after a merger announcement on deal completion. We find the probability of completion increases (decreases) with the favorability of acquirer (target) recommendations. Results from instrumental variables tests support causality running from recommendations to merger outcomes. Additional tests suggest that these relations are driven by target shareholders reassessing the merger offer in response to movements in acquirer and target valuations. We also find that favorablyrecommended firms in a proposed merger underperform following deal resolution, suggesting that investors overreact to post-merger announcement recommendations.

JEL classification: G32; G34; G21

Keywords: Mergers; analysts; merger success; valuation

\footnotetext{
${ }^{\dagger}$ David Becher: Drexel University, Department of Finance, 3220 Market Street, $11^{\text {th }}$ floor, and Fellow, Wharton Financial Institutions Center, University of Pennsylvania, Philadelphia, PA 19104, phone: (215) 895-2274, email: becher@drexel.edu. Jonathan Cohn: University of Texas at Austin, Finance Department, 2110 Speedway Stop B6600, Austin, TX 78712, phone: (512) 232-6827, email: jonathan.cohn@mccombs.utexas.edu. Jennifer Juergens: Drexel University, Department of Finance, 3220 Market Street, $11^{\text {th }}$ floor, Philadelphia, PA 19104, phone: (215) 895-2308, email: j1j54@drexel.edu.

We thank Tom Bates, Gennaro Bernile, Audra Boone, Jie Cai, Naveen Daniel, Eli Fich, Jarrad Harford, Laura Lindsey, Spencer Martin, Tobias Muhlhofer, Micah Officer, Mike Stegemoller, Ralph Walkling, Xiaoyun Yu, Mengxin Zhao, and seminar participants at Arizona State University, Drexel University, Rutgers University, Temple University, Texas A\&M University, Texas Tech University, The University of Kansas, The University of Texas Austin, The University of Texas - Dallas, Villanova University, the Financial Intermediation Research Society conference, the Conference on Financial Economics and Accounting, the Financial Management Association, and the FMA European meetings for helpful comments. We thank Rachel Gordon, Andrew Koch, Kurt Miling, Wenjing Ouyang, and Elisa Scinto for excellent research assistance.
} 
One of the most important questions in finance is how information generated by financial markets impacts real economic decisions. One potentially important source of such information is securities analysts, who collectively produced over 29,000 stock recommendations and 196,000 earnings forecasts in 2012 alone. While these published opinions have been shown to move stock prices, their impact on corporate decisions and hence their real economic consequences remain largely unexplored. ${ }^{1}$

This paper studies the impact of analysts on an important set of real decisions: whether companies complete announced mergers. While most announced deals are ultimately completed, a substantial minority are terminated prior to conclusion by either the acquirer or target. After a merger is announced, stockholders and managers of acquirers and targets may continue to learn about the desirability of the transaction as new information arrives. One potentially important source of such information is stock analysts, who continue to issue recommendations on firms after they announce their intention to merge. As analysts specialize in interpreting complex value-relevant information, these post-merger announcement recommendations (PMARs) are likely to resonate with the parties involved. We analyze the relation between these recommendations and merger outcomes (completion vs. termination).

Our analysis focuses on announced mergers involving publicly-traded U.S. firms from 1993 and 2008. Our main finding is that the probability of deal completion increases (decreases) with the number of favorable (unfavorable) acquirer PMARs and decreases (increases) with the number of favorable (unfavorable) target PMARs. Each additional favorable (unfavorable) PMAR on an acquirer's stock is associated with a $0.9 \%-1.1 \%$ increase $(1.4 \%-2.0 \%$ decrease) in the probability of completion. Each additional favorable (unfavorable) target PMAR is

\footnotetext{
${ }^{1}$ Papers showing that recommendations move stock prices include those by Womack (1996), Barber, Lehavy,
} McNichols, and Trueman (2001), and Loh and Stulz (2011). 
associated with a $1.2 \%-2.2 \%$ decrease $(0.3 \%-1.6 \%$ increase $)$ in completion probability. These magnitudes are substantial relative to an unconditional probability of termination of $14 \%$.

These results indicate that PMARs could impact merger completion decisions. Alternatively, some omitted variable such as public information about a merger's effects on the firms involved could influence both recommendations and deal completion directly, inducing a non-causal relation. We seek further evidence on the causal effect of PMARs using an instrumental variables approach, with three instruments for the favorability of an analyst's recommendation: the analyst's own average recommendation on other stocks, the average recommendation of all other analysts on other firms within the industry, and the average recommendation of the analyst's brokerage house on firms outside the industries of the merger parties. Merger outcomes continue to be related to recommendation favorability when we employ these instruments, consistent with PMARs having a causal effect on outcomes. We discuss the validity and limitations of these instruments in Section III.

We explore two distinct, though not mutually exclusive, causal explanations for the relations we observe, which we term "feedback" and "valuation" explanations. The feedback explanation relates closely to arguments that firms treat financial market responses to their actions as feedback, and recalibrate their actions accordingly (Bond, Goldstein, and Prescott, 2010). Management and shareholders may treat favorable (unfavorable) PMARs on their own firm as positive (negative) signals about their anticipated benefits from a proposed transaction, increasing (decreasing) the likelihood they ultimately approve the deal. This explanation would account for the positive relation of merger completion probability with acquirer PMAR favorability that we observe, but appears at odds with the negative relation with target PMAR favorability, as a target should also update positively on more favorable PMARs on itself. As a 
result, if feedback is at least partly responsible for the connection between PMARs and merger outcomes, it must be based on the acquirer rather than the target making use of this feedback.

The valuation explanation is based on the idea that movements in the valuations of the firms involved in a merger impact the attractiveness of a given offer to each of the parties. An increase in a target's independent value makes a given offer less attractive to target shareholders but more attractive to the acquirer. In a stock merger with a fixed exchange ratio of acquirer to target shares (approximately $72 \%$ of our sample), an increase in acquirer value makes a given offer more attractive to the target but less attractive to the acquirer. While the parties can, in principle, renegotiate an offer to undo the effects of any valuation movements, various frictions are likely to make such renegotiation costly. In this case, these valuation movements may impact each party's decision to complete a transaction. ${ }^{2}$ The positive relation of deal completion likelihood with acquirer PMAR favorability and its negative relation with target PMAR favorability are consistent with targets specifically reassessing offer attractiveness in response to valuation movements. Thus we focus on this case, though we weigh the possibility that the acquirer reassesses the attractiveness of the deal as well. ${ }^{3}$ We discuss both the feedback and valuation explanations in more detail in Section IV.

We implement three tests to further evaluate each of these explanations. In the first, we estimate a multinomial logistic model of merger outcomes where we treat termination by the acquirer and the target as distinct outcomes. We find that a target is less (more) likely to terminate a deal following favorable (unfavorable) acquirer PMARs and unfavorable (favorable)

\footnotetext{
${ }^{2}$ Consistent with such renegotiation being costly, we find bid revisions in fewer than $5 \%$ of our sample, where deals are classified as having a revision if the final price to target shareholders varies from the initial offer price (SDC).

${ }^{3}$ This is also consistent with existing evidence that firms are more likely to become acquirers if their valuations are high (Rhodes-Kropf, Robinson, and Viswanathan, 2005) and more likely to become targets if their valuations are low (Edmans, Goldstein, and Jiang, 2012).
} 
target PMARs (though the latter fall short of statistical significant). This is further evidence of the target reassessing the attractiveness of the merger offer in response to valuation shocks (i.e., the valuation explanation). Inconsistent with the feedback explanation, we do not find that either party's termination decision is negatively related to the favorability of PMARs on itself.

In the second test, we examine offers including at least some acquirer stock ("stock offers") and those consisting only of cash ("cash offers") separately. The valuation explanation predicts a positive relation between merger completion and acquirer PMAR favorability only in stock offers, as the offer value is only sensitive to the value of the acquirer's stock in these cases. The feedback explanation, on the other hand, potentially applies to all deals, as acquirer managers and shareholders may learn from acquirer PMARs about their anticipated gains from the merger in either case. Supporting the valuation explanation, we find that the positive relation between merger outcomes and acquirer PMAR favorability is strong when the acquirer's offer includes stock but is weak and statistically insignificant in pure cash mergers.

In the third test, we examine how the relation between merger outcomes and acquirer PMARs varies with a target's relative size. All else equal, the larger the target is relative to the acquirer, the more material the merger is for acquirer value, and the more likely a PMAR reflects an analyst's assessment of the value the merger will create for the acquirer. The feedback explanation then predicts a stronger relation between acquirer PMARs and merger completion when the target is relatively larger. We do not find that this is the case. While none of these tests is perfect, they collectively provide more support for the valuation explanation than the feedback explanation in driving observed relations between PMARs and merger completion.

Finally, we study the relation between post-merger resolution returns and PMAR favorability. While PMARs may influence merger outcomes because they are informative about 
the fundamentals of the firms involved, Shleifer and Vishny (2003) and Rhodes-Kropf and Viswanathan (2004) argue that even non-fundamental components of values can impact merger decisions. We find acquirers with relatively favorable PMARs substantially underperform those with unfavorable ones over various horizons after deal completion or termination. Differences in calendar-time portfolio abnormal returns exceed $10 \%$ over a one- or two-year horizon. These results combined with evidence the market responds positively (negatively) to favorable (unfavorable) PMARs at the time they are issued suggests the market overreacts to PMARs, and represents evidence that non-fundamental value movements impact merger completion decisions.

Our results indicate that analyst recommendations have real consequences for merger outcomes. Recent papers tend to focus on the effects of analyst coverage (as opposed to the tenor of the recommendations) on real firm decisions. Doukas, Kim, and Pantzalis (2008) document a positive relation between analyst coverage and firm investment, arguing firms with more analyst coverage face fewer information asymmetries and therefore a lower cost of capital. Derrien and Kecskes (2013) document similar results using broker closures and mergers as exogenous sources of variation in analyst coverage. Degeorge, Derrien, Kecskes, and Michenaud (2013) and Chen, Harford, and Lin (2014) show analysts' preferences for certain types of corporate policies (e.g. investment, financing, payout, or governance) influence the decisions of firms that they cover. He and Tian (2013) find that more analyst coverage results in less patenting and argue this is driven by the pressure analysts exert on managers to focus on the short run. Ours is the first paper that we are aware of to examine the impact of analyst opinions on merger outcomes and to assess the real consequences of the favorability of analyst opinions. ${ }^{4}$

\footnotetext{
${ }^{4}$ Bradshaw, Richardson, and Sloan (2006) show that decisions to issue equity and repurchase shares are related to the optimism of analysts' forecasts and recommendations. Bates, Chang, and Lindsey (2012) find that reductions in
} 
Our results also contribute to the literature connecting valuation and merger decisions. Edmans et al. (2012) show that a lower stock price increases the likelihood a firm is acquired, using mutual fund redemptions to instrument for firm price. Rhodes-Kropf et al. (2005) find evidence overvaluation of a firm's stock is an important driver of its decision to become an acquirer. These papers relate to the decision to pursue a merger. Our results suggest that information about firm values affects the decision to complete a proposed merger as well.

\section{Data and Sample Selection}

\section{II.A. Merger Sample}

To test an association between PMARs and deal completion, we create a set of completed and terminated U.S. mergers and tender offers. ${ }^{5}$ We collect all deals between 1993 and 2008 from Thomson/SDC Mergers \& Acquisitions database where both the acquirer and target are publicly-traded. 407 deals announced or resolved in 2002 are excluded because the Global Research Analyst Settlement (GRAS) was implemented that year. GRAS, which was intended to address conflicts of interest within investment banks, resulted in numerous recommendation changes that likely had little to do with changes in analysts' perceptions of firm value. ${ }^{6}$

We also exclude non-U.S. and private acquirers or targets, divisions, divestitures, spinoffs, leveraged buyouts, liquidations, non-merger observations (i.e. majority interest), unit trusts, REITs, and ADRs, and retain only deals where the form was merger or acquisition. This yields

information asymmetries due to analyst coverage cause a positive relation between analyst coverage and cash holdings. However, the decisions studied in these papers are financial rather than real.

${ }^{5}$ Tender offers constitute only $10 \%$ of the sample. As most of transactions are mergers, we use the term merger to refer to all transactions in our sample (Officer, 2003; Moeller, Schlingemann, and Stulz, 2004).

${ }^{6}$ Kadan, Madureira, Wang, and Zach (2009) identify five days where at least one brokerage firm (for a total of eight firms) did a rescale. We identify at least 21 days in 2002 where the number of daily recommendation revisions by firms exceeded the mean of three by 10 standard deviations. Not all brokerage firms had mandatory GRAS transition dates, therefore, the migration to more conservative recommendations is difficult to pinpoint for many firms. We have verified that our results are qualitatively unchanged if we include these 407 mergers. Moreover, we split the sample into pre- and post-GRAS samples and obtain quantitatively similar results to our main analyses. 
an initial sample of 5,811 announcements. In transactions involving competing bids, analysis of a specific acquirer's takeover attempt is complicated by the possibility that a different acquirer may take over the target. To be conservative, we eliminate 430 deals in which we observe multiple acquirers for the same target. Our final sample consists of 5,381 announced mergers, including 4,625 completed and 756 terminated deals.

From SDC we gather information on mergers, including the names, cusips, tickers, acquirer and target SIC codes, deal form (merger or tender offer), merger outcome (completed or terminated), days to resolution, deal value, consideration offered, whether a collar offer is made, bid revisions, and the number and names of merger advisors and advisory fees. Due to the incompleteness of SDC data, we supplement the SDC data with information on merger status, announcement and resolution dates, deal value, consideration offered, termination reason, collar type, advisors, and fees using data from Lexis-Nexis, Factiva, Dow Jones Newswire, SEC filings, and Mergers \& Acquisitions. We attempt to match each acquirer and target to CRSP and Compustat by cusip if it is available and by ticker if not. We verify the accuracy of matches by comparing company names, and where we are unable to obtain a match using cusips or tickers, we hand-match by company name. We are able to correctly match 5,034 acquirers and 4,649 targets. We obtain financial variables from Compustat and stock return data from CRSP. Although our initial tests rely on the full sample of 5,381 announced transactions, we note our main analyses encompass 3,596 deals where all data is available for both acquirers and targets. Table I details merger characteristics.

Insert Table I here 
Of the 5,381 announced mergers in our sample, $86 \%$ are ultimately completely and $14 \%$ are terminated. Of these 756 terminated deals, $168(22 \%), 279(37 \%)$, and $76(10 \%)$ are terminated by acquirers, targets, and for regulatory reasons, respectively. ${ }^{7}$ We are unable to assign the exact cause of termination for the remaining 219 terminated deals. In many of these cases, accounts indicate that the two sides came to a mutual agreement to terminate.

The acquirer offers at least some stock in $76 \%$ of transactions, and the offer includes only stock in $41 \%$ of transactions. The vast majority (95\%) of offers including at least some stock have fixed exchange ratios (i.e., a certain number of acquirer shares for each share of the target's stock). The remaining 5\% have fixed dollar amounts (i.e., a certain dollar amount of acquirer stock at prevailing prices for each share of the target's stock). $11 \%$ of the stock offers in our sample include collars that constrain the dollar value of the merger offer if the acquirer's stock price moves outside of preset bounds. $260(5 \%)$ of the offers are revised at some point prior to resolution. In addition to merger offers, our sample includes 551 tender offers, representing about $10 \%$ of the transactions in the sample. ${ }^{8}$

The average transaction value is $\$ 1.15$ billion, and the acquirer offers an average premium of $45 \%$ relative to the target's price four weeks prior to announcement as reported by SDC. Consistent with prior studies (e.g., Betton, Eckbo, and Thorburn, 2008), targets experience positive announcement returns (three-day CARs) of nearly 19\%. On average, acquirers experience a negative $1 \%$ announcement return (p-value of 0.03 ), but there is a run-up in acquirer stock price of about $2 \%$ between 30 and 5 days prior to deal announcement (p-value of 0.01). On average, 130 days elapses between merger announcement and resolution.

\footnotetext{
${ }^{7}$ As the regulatory terminations are unlikely to be related to analyst recommendation revisions, we remove these 76 transactions as a robustness check, and our results are qualitatively unchanged.

${ }^{8}$ We obtain almost identical results throughout our analysis if we exclude offers with fixed dollar values, offers with collars, offers where the initial bid is revised, tender offers, and any combination of these cases.
} 


\section{II.B. Analyst Recommendations}

We obtain analyst recommendations from I/B/E/S (Thomson Financial) from 1993 to 2008 and retain a firm's cusip, ticker, and name, brokerage house, analyst name, date of current and prior recommendations, and standardized current and prior recommendation codes $(1=$ strong buy; 2 = buy; $3=$ hold; $4=$ sell; and $5=$ strong sell). As with the CRSP and Compustat data, we use cusips, tickers, and company names to match firms between SDC and I/B/E/S. We collect all recommendations on the firms involved from 50 days pre-merger announcement through resolution (completion or termination). Our main analyses focus on post-merger announcement recommendations (PMARs), which are all recommendations issued on either an acquirer or target from the first day after an announcement (Day 1) until resolution.

Since we are interested in how innovations to recommendations impact merger outcomes, we focus on recommendation changes (e.g., upgrades and downgrades) as well as initiations rather than recommendation levels. Upgrades (e.g., from hold to buy) and initiations with a strong buy are considered "favorable" recommendations, while downgrades (e.g., from hold to sell) and initiations with a hold, sell, or strong sell are "unfavorable" recommendations. ${ }^{9}$ Recommendations that do not fall into the standard ratings system are eliminated.

Of the 5,381 deals in our sample, 3,332 acquirers and 2,124 targets have at least one PMAR change or initiation. Table II details PMAR characteristics and 3-day cumulative abnormal returns. In computing recommendation returns (only), we exclude PMARs for the first five days after a merger announcement to avoid contamination from returns associated with the

\footnotetext{
${ }^{9}$ We exclude 1,487 initiations with a buy (Dunbar, Hwang, and Shastri 1999) and 1,644 reiterations (Barber, et al., 2001) as the direction is ambiguous. While GRAS was designed to shift the distribution of recommendations away from buy to hold, recommendations only partially adjusted, and for most of our sample, buys were implicitly considered to be hold recommendations (Kadan, et al; 2009).
} 
deal itself. ${ }^{10}$ Pre-announcement recommendations (issued between 50 and one day before a merger) are shown for comparison.

Insert Table II here

Recommendation changes are in Panel A, while initiations of coverage are in Panel B. From the day after a merger announcement through resolution, acquirers receive 3,670 upgrades, 3,398 downgrades, 1,128 favorable initiations, and 1,291 unfavorable initiations. Targets receive 813 upgrades, 1,559 downgrades, 158 favorable initiations, and 378 unfavorable initiations.

Prior studies document analyst recommendations tend to move stock prices in general (Stickel, 1995; Womack, 1996; Barber, et al., 2001). Since our study focuses on how PMARs affect merger outcomes through their impact on the valuations of the acquirer and target, it is important these particular recommendations affect acquirer and target stock prices beyond the announcement effect. If recommendations were simply a response to a deal announcement, the information content and expected return should be low. Consistent with prior studies, we observe significantly positive returns for favorable PMAR changes $(1.51 \%$ for acquirers and $0.55 \%$ for targets) and significantly negative returns for unfavorable ones $(-2.89 \%$ for acquirers and $-0.60 \%$ for targets). Similar results are obtained if we examine PMA initiations (Panel B). ${ }^{11}$

Figure 1 displays the timing of PMARs relative to the announcement date both in absolute number of days (Panel A) and percentage of days elapsed between announcement and

\footnotetext{
${ }^{10} \mathrm{We}$ obtain qualitatively similar results if we include these five days.

${ }^{11}$ Although multi-level changes are less frequent than single-level revisions, they represent a considerable portion of all recommendation changes, and generate a larger price response on average (i.e., acquirer returns for changes from strong buy to buy are $-3.04 \%(\mathrm{~N}=936)$ compared to $-4.01 \%(\mathrm{~N}=731)$ for strong buy to hold revisions and are significantly different at the $5 \%$ level).
} 
resolution (Panel B). ${ }^{12}$ There is a clear spike in both acquirer and target recommendations immediately after a merger announcement, regardless of the panel examined. Since a prospective deal has important implications for the firms involved, analysts are likely to reevaluate stocks shortly after announcement. We obtain similar figures if we exclude deals resolved within 20 days, suggesting the patterns in Figure 1 are not driven by quickly-resolved transactions.

\section{Insert Figure I here}

To better understand the basis for PMARs, we analyze full-text research reports for firms involved in a randomly-selected sample of approximately 300 deals from 1999 to 2008 from Thomson One. ${ }^{13}$ We only examine the subset of deals where both acquirers and targets have analyst coverage, and randomly draw 30 transactions per year. If a report on either merger party was unavailable between the announcement and resolution, the observation was replaced with another drawn from the same year, but not previously used. If multiple reports were available in the window, one was randomly selected. Appendix B (Panel A) provides details on the reports.

Mergers are at least mentioned in $93 \%$ of the acquirer reports, and the possible consequences are discussed in the context of the analyst's recommendation on the firm in $57 \%$ of acquirer reports. $80 \%$ of acquirer reports provide some discourse on possible synergies or fit with the target, while $26 \%$ adopted a tone (positive or negative) on the price being offered. Very few $(2 \%)$ mentioned the possibility of competing bids.

Similarly, in $95 \%$ of target reports, mergers are mentioned. Many of the remaining 5\% appear to be boiler plate analyses of firm fundamentals that do not consider other factors. $61 \%$

\footnotetext{
${ }^{12}$ See Figure 2 in Malmendier, Opp, and Saidi (2012) for a similar approach.

${ }^{13}$ Due to limited sample availability prior to 1999 , we constrain our sampling window between 1999 and 2008 . We further note that the sample is not truly random as we require reports exist for both acquirers and targets.
} 
discuss merger consequences in the context of an analyst's recommendation. In many though not all cases, analysts appear to automatically change the target recommendation to neutral to reflect the fact that a transaction is likely to close, and the stock price has already adjusted to the offer price. Given the average analyst rating is generally more favorable than neutral, this causes the average change to be a downgrade. Initiations on the target also tend to be neutral (which is less favorable than average initiations overall) for the same reason.

Possible synergies and fit are also discussed in 55\% of target reports. Virtually all of these involve deals in which the acquirer offers at least some stock (i.e., target shareholders will own stakes in the acquirer post-merger). Only $7 \%$ adopt any tone on the price being offered, and again, very few (3\%) mention the possibility of competing bids. We refer back to some of these details later in our assessment of the effects of PMARs on merger completion decisions.

\section{Post-Announcement Analyst Recommendations and Merger Completion}

In this section, we analyze how the probability that a merger is completed varies with the favorability of PMA analyst recommendations. We also use an instrumental variables approach to assess causality in the relation between recommendations and completion.

\section{III.A. Analyst Recommendations and the Probability of Merger Completion}

We begin by analyzing the relation between the favorability of PMARs and likelihood of deal completion. We estimate logistic regressions in which the dependent variable is an indicator taking a value of one if a deal is completed and zero if it is terminated. We include four primary explanatory variables in all specifications: the number of favorable and unfavorable PMARs separately for the acquirer and target. We further control for the number of analysts 
covering an acquirer and target to remove the potentially contaminating effects of coverage amount. All models include year and industry indicators. Table III shows the results.

\section{Insert Table III here}

In this and later logistic regressions, we report marginal effects evaluated at the means of the explanatory variables. p-values from a two-sided z-test are shown to the right of each marginal effect estimate. ${ }^{14}$ In the first model, we include only the number of favorable and unfavorable acquirer and target PMARs and total number of analysts covering the acquirer and target. The marginal effects of the number of favorable acquirer and unfavorable target PMARs are significantly positive, while those of the number of unfavorable acquirer and favorable target PMARs are both significantly negative. Because these explanatory variables are count variables, the marginal effects represent the estimated effect of one additional PMAR of the relevant type on the probability of merger completion. One additional favorable (unfavorable) acquirer PMAR is associated with a $1.09 \%$ increase $(1.95 \%$ decrease) in completion probability, and one more favorable (unfavorable) target PMAR is associated with a $2.15 \%$ decrease $(1.60 \%$ increase) in completion probability. These associations are economically important relative to the unconditional probability of termination of $14 \%$ in our sample.

We also find that the likelihood of merger completion increases (decreases) significantly with the number of analysts covering the acquirer (target). While not the focus of our paper, one possible explanation for the effect of the number of acquirer analysts could be that more analyst

\footnotetext{
${ }^{14}$ Cross-sectional correlation in error terms at the acquirer or target industry level could cause underestimation of standard errors and hence overestimation of statistical significance levels. This could occur, for example, if merger completion probability systematically increases or decreases during an industry merger wave. Clustering standard errors at the industry level would help to address this. However, it is unclear whether to cluster by the acquirer's or target's industry. Thus, we report unclustered standard errors, though we find similar levels of statistical significance in all of our tests if we cluster by target industry, acquirer industry, target industry-year, or acquirer industry-year.
} 
coverage reduces information asymmetry, increasing the likelihood that both parties accept a transaction. However, with reduced information asymmetry, more visible targets potentially have more outside options, which is consistent with the negative effect for target coverage.

In the second model of Table III, we include additional controls (detailed in Appendix A). Merger characteristics include deal size (log of transaction value), number of acquirer and target advisors, days until resolution, run-up and announcement period returns, and indicators for method of payment, cash tender offers, fixed or floating collars, horizontal deals, and merger programs. Analyst/recommendation controls include average recommendation levels for targets and acquirers, total number of pre-announcement and PMARs (non-directional), and if the same analyst provides recommendations for the acquirer and target. In this expanded model, the marginal effects of some of the acquirer and target PMAR favorability variables decrease slightly in magnitude but retain their signs, and all except the marginal effect of unfavorable target PMARs remain statistically significant at the one percent level.

Another possible driver of deal completion is the incentives of the investment banks that advise the merger parties. Almost all investment banks employ stock analysts, who in many cases cover one or both of the merger parties. Several papers, including Rau (2000), find advisor market share (function of deal count) impacts bank reputation and primarily charge contingency fees to capitalize on completion. ${ }^{15}$ To test if advising banks' incentives influence deal outcomes, we hand-collect data on acquirer and target advisor fees, and include two fee indicators as explanatory variables in the third model (our base model for the remainder of the paper).

\footnotetext{
${ }^{15}$ In addition to merger fees, investment banks may also derive financing fees in completed deals. To capture these effects, we collect data on financing arrangements; however, in only $4 \%$ of our mergers was a financing agreement disclosed and in almost no instance was the actual financing fee disclosed.
} 
The marginal effects of the target and acquirer fee variables are positive and statistically significant at the five percent level or better. This is consistent with banks taking more actions to facilitate deal completion when their compensation is explicitly linked to completion (McLaughlin, 1992; Rau, 2000). This is further reinforced by the fact that the marginal effects of acquirer and target recommendations, while retaining the same statistical significance as in Model 2, decrease slightly when fee variables are included.

\section{III.B. Instrumental variables approach}

While merger outcomes exhibit robust relations with PMARs, these relations need not reflect the causal effect of PMARs. The challenge in inferring causality is that the decision to issue a PMAR could be endogenous with respect to deal outcomes. For example, signals from other sources that cause analysts to update recommendations on one of the merger parties could also directly impact completion. Positive signals about merger gains may both cause analysts to upgrade an acquirer while increasing the likelihood the acquirer completes a deal. Alternatively, a positive signal about deal completion could cause analysts to positively update on the acquirer. Either of these effects could induce a non-causal relation between deal outcomes and PMARs.

We attempt to address this potential endogeneity problem by using a two-stage instrumental variables approach. In the first stage, we predict the number of favorable and unfavorable acquirer and target PMARs. We estimate two logistic models, one for acquirers and one for targets, in which the dependent variable is an indicator equal to one if a recommendation is favorable and zero if it is unfavorable. The explanatory variables are three instruments, along with all of explanatory variables in Model 3 of Table III, excluding the PMAR variables. ${ }^{16}$

\footnotetext{
${ }^{16}$ In untabulated results, we test whether information arriving with a merger announcement itself might drive analyst behavior by examining the relation between acquirer announcement returns and PMARs and observe no clear pattern. The ratio of upgrades to total recommendation revisions is approximately 53\% for the highest and lowest
} 
Our first instrument is an analyst's average (AA) recommendation for her coverage universe (excluding an acquirer and/or target). If individual analysts exhibit systematic optimism or pessimism in their recommendations, then an analyst's recommendation regarding one firm will be correlated with her others. Our second instrument is average industry (IA) recommendation (excluding the acquirer and/or target) across all other analysts at the time. If analysts collectively exhibit systematic optimism or pessimism about specific industries, then an analyst's recommendation regarding a specific firm should be related to other analyst recommendations on firms in that industry. Our third instrument is the average recommendation of an analyst's brokerage (BA) for all firms outside the acquirer's and target's industries. If brokerages exhibit systematic optimism or pessimism, then an analyst's recommendation should be related to other analyst recommendations issued by the brokerage firm. These instruments are all measured six months prior to the merger announcement.

In the second stage, we re-estimate model 3 of Table III replacing favorable and unfavorable PMARs with the predicted number of favorable acquirer or target PMARs from the first stage. As we condition on a recommendation occurring to construct samples in the first stage, the fitted value is the number of predicted recommendations that are favorable as opposed to unfavorable, and the second stage does not include a predicted number of unfavorable recommendations separately. Table IV presents results from first and second stage regressions.

Insert Table IV here

announcement return quintiles (average 3-day returns are $9.01 \%$ and $-11.19 \%$, respectively), and approximately $46 \%$ for the middle three quintiles. Signals arriving concurrently with a merger announcement, which could be related to the eventual merger outcome, do not appear to impact acquirer PMARs, and thus are unlikely to drive the observed relation between PMARs and merger completion. 
Columns 1 and 2 of Panel A detail results from the first stage regressions. All three instruments exhibit independent predictive power over the favorability of PMARs, suggesting the relevance condition for instrumental variables is satisfied. AA and IA both positively predict the favorability of an acquirer PMAR at five percent or better level of statistical significance. IA and BA positively predict the favorability of a target PMAR at the five percent or better level of statistical significance. F-tests for weak instruments based on Stock and Yogo (2005) reject the null hypothesis that the instruments have no explanatory power over acquirer and target PMARs with p-values in both cases of less than 0.001 .

The third column of Panel A presents results from the second stage. The probability of deal completion is positively (negatively) related to the predicted number of favorable acquirer (target) recommendations (p-values are 0.06 and 0.05 , respectively). Estimated at the means of the variables, the marginal effect of one extra predicted favorable acquirer PMAR (versus an extra unfavorable prediction) is a $1.05 \%$ increase in the probability of merger completion, while the marginal effect of one extra favorable target PMAR is $-0.76 \% .{ }^{17}$

For these estimates to represent the effect of PMARs on the probability of merger completion, the "exclusion restriction" must also be satisfied. That is, AA, IA, and BA should relate to merger outcomes only through their relation with the PMAR regarding the acquirer or target in question. One concern is that IA and, to a degree, AA (because analysts tend to specialize by industry) capture information about the state of an industry that might be related to the level of merger activity within that industry. This is potentially a problem if firms are more likely to complete deals during an industry merger wave because expected returns are higher in

\footnotetext{
${ }^{17}$ As an alternative approach, we compute the average probability of a favorable recommendation change from the fitted values in the first stage and use this as the explanatory variable in the second stage instead of the predicted number of favorable recommendation changes. The results are quantitatively similar in terms of the effect of a one standard deviation change in the explanatory variables, and the statistical significance levels remain the same.
} 
these cases, or less likely because of the increased likelihood of alternative bidders. Either of these effects could contaminate our instrumental variables test.

We address this concern by repeating the two stages using only BA as an instrument for the number of favorable PMARs. Since BA represents the average recommendation favorability by a given an analyst's brokerage on firms in other industries, it is less likely to capture information about the state of merger activity in the industry in question than IA and AA. The results are shown in Panel B of Table IV. BA continues to positively predict the favorability of PMARs, though again only its relation with target PMAR favorability is statistically significant (p-value 0.02). The second stage regression continues to show deal completion is more likely when the fitted number of favorable acquirer (target) recommendations is higher (lower). While BA by construction does not relate to the brokerages opinion of the acquirer's or target's industry directly, it is still possible that the types of firms a brokerage generally covers are similar to the acquirer and/or target even across industries, which would raise concerns about the exclusion restriction. Ultimately, it is difficult to completely rule out the contaminating effects of an omitted variable. However, the instrumental variables tests do provide further support for the argument that PMARs affect merger outcomes.

\section{Explanations for Relations between PMARs and Merger Outcomes}

In this section, we explore two possible causal explanations for the relations between PMARs and merger outcomes documented in Section III. The first (the "feedback" explanation) is based on the idea that firms recalibrate their actions based on feedback from financial markets. A good acquisition can create substantial value while a bad one can destroy substantial value. Stock analysts are therefore almost certain to take into account the impact that the completion of 
a proposed deal will have when issuing PMARs. Indeed, as noted in Section II.B, 57\% of reports on acquirers and $61 \%$ of reports on targets mention the potential impact of a merger when discussing the rationale for the recommendation made.

If acquirer management and shareholders treat acquirer PMARs as signals about the expected benefits of a merger for an acquirer, then a favorable (unfavorable) acquirer PMAR should increase their willingness to complete a deal. This would explain the positive (negative) relation we observe between deal completion and number of favorable (unfavorable) acquirer PMARs. The same logic applied to a target should lead to a positive (negative) relation between merger completion and favorable (unfavorable) target PMARs, which is the opposite of what we find. ${ }^{18}$ We therefore focus primarily on feedback from PMARs into the acquirer's decision to complete a merger when further assessing the relevance of the feedback explanation.

The second explanation ("valuation" explanation) is based on the idea that valuations are important drivers of merger decisions. In a completed deal, target shareholders surrender direct ownership and, at least in stock mergers (76\% of our sample), receive an ownership stake in the acquirer in exchange. Acquirer shareholders, alternatively, gain ownership of a target and, again at least in stock deals, surrender an ownership stake in their own firm to target shareholders. Thus, each party in a proposed merger is likely to weigh the values of both the target and a given stake in the acquirer in assessing the merger offer's attractiveness. PMARs then may impact the completion decision of either party simply by moving valuations of the firms involved. ${ }^{19}$

\footnotetext{
${ }^{18}$ Note that the feedback explanation from the target perspective only applies in deals where target shareholders receive at least some stock in the acquirer. In all-cash deals, the value of the merger from the target's standpoint is known with certainty. The acquirer offers at least some stock in most $(76 \%)$ of the mergers in our sample, and we show later that the results continue to disagree with the feedback predictions when we look only at stock mergers.

${ }^{19}$ In principle, several factors could limit the effect of valuation movements on merger outcomes. For example, if firms can renegotiate deal terms costlessly, they can undo the effects of movements in either acquirer or target value. However, the process of renegotiation is fraught with frictions likely to make it costly. Indeed, we find evidence of renegotiation after a merger announcement in only 5\% of our sample. Valuation movements should also be
} 
An increase in the valuation of one's own firm makes a given offer less attractive, while an increase in the valuation of the other firm makes a given offer more attractive. Reassessment by the target in response to a valuation shift then would explain both the positive relation between acquirer PMAR favorability and deal completion likelihood and the negative relation between target PMAR favorability and completion likelihood. Reassessment by the acquirer after valuation changes, on the other hand, is inconsistent with both of these findings. We therefore focus on the valuation effects of PMARs on the target's merger decision when further assessing the empirical relevance of the valuation explanation.

Both the feedback and valuation explanations appear to be consistent with at least some of the relations between merger completion probability and acquirer and target PMARs that we observe. We next present three tests to further assess the relevance of each of these explanations. As a reference, Table $\mathrm{V}$ presents the predictions of both explanations for each of the tests. The table also presents (in the first few rows) the predicted signs of the relations between deal completion likelihood and acquirer and target PMAR favorability that we just discussed. ${ }^{20}$

Insert Table V here

\section{IV.A. Test 1: Identity of party terminating merger}

Either an acquirer or target can elect to terminate a deal. Our first test involves examining acquirer and target termination decisions separately. As noted, the feedback explanation relates

irrelevant if the value of consideration (rather than the exchange ratio of shares) is fixed at merger announcement; yet we only find $3 \%$ of stock offers involve fixed values. Finally, even in fixed exchange ratio offers, collars may limit the impact on valuation movements. We find evidence of collars in only $11 \%$ of the stock deals in our sample.

${ }^{20}$ As noted, we consider only the feedback explanation based on feedback from PMARs to acquirers and the valuation explanation based on reassessment by targets in these tests, as only these explanations are consistent with the results in Section III. This is reflected in the predictions shown in the table. However, we find no support for either target-driven feedback or acquirer-driven valuation explanations in these tests. 
to acquirer termination decisions and predicts that favorable (unfavorable) acquirer PMARs decrease (increase) the likelihood of acquirer termination. It makes no predictions about the impact of favorable or unfavorable target PMARs. The valuation explanation, on the other hand, relates to target termination decisions. It predicts that favorable (unfavorable) acquirer PMARs decrease (increase) target termination likelihood, while favorable (unfavorable) target PMARs increase (decrease) that likelihood. The second set of rows in Table V shows these predictions.

We test both of these sets of predictions by estimating a multinomial logistic model. The dependent variable is merger outcome, which can be completion, termination by the acquirer, or termination by the target. As Table I shows, acquirers and targets terminate mergers in 168 and 279 cases, respectively. We remove any mergers terminated for regulatory reasons and those where we cannot determine the cause of termination unambiguously from this test. The explanatory variables of interest continue to be the number of favorable and unfavorable acquirer and target PMARs. Table VI details the results from this multinomial logistic estimation.

Insert Table VI here

The base case is completion. The first column details marginal effects of the determinants of acquirer termination relative to the base case, while the second column reports the marginal effects of the determinants of target termination. Note that we are modeling the probability of termination rather than completion here, so the signs of the marginal effects have the opposite interpretation of those in Tables III and IV (this is reflected in the predictions in Table V).

The first column illustrates that acquirer termination is negatively related to the number of favorable (unfavorable) PMA acquirer (target) recommendations. While the signs of these marginal effects are consistent with the feedback explanation, they are statistically insignificant 
and small in magnitude. The second column details target termination is negatively (positively) related to the number of favorable (unfavorable) acquirer PMARs. These relations are large and statistically significant at the five and one percent levels, respectively. ${ }^{21}$ The signs of the marginal effects of target PMARs on target termination are also consistent with those in Table III, though they fall short of statistical significance. Overall, this test provides support for the valuation explanation but not for the feedback explanation.

\section{IV.B. Test 2: Stock- vs. cash-based transactions}

In our second test, we examine the relation between merger completion and acquirer PMARs in stock and all-cash mergers separately. According to the valuation explanation, acquirer PMARs influence deal outcomes by altering a target's perception of the value of an acquirer's stock and hence the value of the offer. If the valuation explanation drives the relation between merger completion and acquirer PMARs, then we should only observe this relation in transactions involving at least some stock. This explanation makes no clear prediction about differences between stock and cash mergers in the relation of merger outcome to target PMARs, as target shareholders surrender their stock in the target in both cases.

It is less clear what differences, if any, the feedback explanation predicts between cash and stock mergers. One might argue an acquirer could learn from recommendations about the deal regardless of method of payment, and therefore the feedback explanation should predict no difference between the two. However, target shareholders share in any increases in expectations about post-merger acquirer value if a stock merger is completed, while such gains accrue solely to acquirer shareholders in a cash deal. Part of such gains then should impact target rather than

\footnotetext{
${ }^{21}$ These marginal effects are smaller than those in Table III because they represent the sensitivity of only one reason for termination to PMARs. In untabulated tests, we find similar relations between the likelihood of termination by an undetermined party and acquirer PMARs. This may indicate that the target is responsible for a majority of these unclassified terminations, though we have no way of verifying this.
} 
acquirer valuation, and analysts might therefore react more mutedly to information about the anticipated effect of a merger on acquirer value. In contrast to the valuation explanation, the feedback explanation would appear then to, if anything, predict stronger relations between merger completion and acquirer PMARs in cash mergers than in stock mergers. These predictions are shown in the third set of rows in Table V.

To examine the relation between merger completion and PMARs in cash and stock mergers separately, we classify each deal as a stock deal if the offer includes at least some acquirer stock, and a cash deal if it does not. We then rerun our base model (Model 3 of Table III) using each of the two resulting samples. Table VII presents the results.

\section{Insert Table VII here}

For stock deals (model 1), the probability of completion is positively (negatively) related to the number of favorable (unfavorable) acquirer PMARs, consistent with the results in Table III. In pure cash deals (model 2); however, there is no significant relation between the probability of completion and the number of favorable or unfavorable acquirer PMARs. The results for stock-financed deals support the role of the valuation effect in driving relations between completion and the favorability of acquirer PMARs. ${ }^{22}$

If, as this test suggests, the valuation explanation represents at least part of the reason for relations between acquirer PMARs and merger outcomes, then IV results (Table IV) and multinomial logistic results (Table VI) should hold if we examine only stock deals. We therefore

\footnotetext{
${ }^{22}$ One potential concern with this test is that there are considerably more stock than cash mergers in our sample. Thus, we may have more power to test the relation of merger outcomes to PMARs in stock deals than in cash deals. In an untabulated test, we construct a matched sample of stock and cash deals, and obtain virtually identical results to those in Table VI using this matched sample.
} 
rerun these tests for stock mergers only (Table VIII). Both sets of results remain largely unchanged if we restrict the sample to stock deals and again support the valuation explanation.

\section{Insert Table VIII here}

\section{IV.C. Test 3: Relative target size}

In our third test, we examine how the relation between merger completion probability and PMARs varies with the relative sizes of the target and acquirer. Other things being equal, the larger the target is relative to the acquirer, the larger the impact of the merger on the acquirer. Therefore, novel information about the value of the merger to the acquirer is more likely to be material if the target is larger. The feedback explanation then would suggest that the sensitivity of merger completion to acquirer PMARs should be stronger when the target is larger in relative size. It is less clear what the valuation explanation would predict about variation with relative target size. One possibility is that firm size is correlated with the amount of information available and hence the impact of a recommendation on assessment of its value. We address this concern directly by accounting for absolute target size directly in our analysis. Thus the fourth set of rows in Table $\mathrm{V}$ only shows predictions for the feedback explanation.

To test variation in the relation between merger outcomes and PMARs with relative target size, we first define Absolute Target Size and Absolute Acquirer Size as the market values of the target's and acquirer's equity computed as stock price three months prior to the merger announcement date multiplied by shares outstanding from CRSP if available and augmented by 
SDC when missing. We use this measure of size because it is the most comprehensive measure of target size that we have. ${ }^{23}$ We then calculate Relative Target Size as

$$
\text { Relative Target Size }=\frac{\text { Absolute Target Size }}{\text { Absolute Target Size }+ \text { Absolute Acquirer Size }} \text {. }
$$

We estimate the same three logistic models shown in Table III, except that we add Relative Target Size and Absolute Target Size as well as their interactions with each of the analyst recommendation variables (including numbers of acquirer and target analysts). ${ }^{24}$ Table IX presents the results of this test.

\section{Insert Table IX here}

The marginal effects of the interactions of PMARs with relative target size are generally statistically insignificant. While the sign of the marginal effect of the interaction with number of unfavorable acquirer PMARs is consistent with the feedback explanation, the one with the number of favorable acquirer PMARs has the wrong sign. Tests of differences in sensitivity of completion to acquirer PMARs with relative target size do not support the feedback explanation.

Overall, the tests in this section provide significantly more support for the valuation explanation than for the feedback explanation. Of course it is impossible to perfectly isolate the effects of each explanation. Nevertheless, our results provide consistent support for the argument that PMARs affect merger outcomes by altering the desirability of the transaction from the target's standpoint through their impact on acquirer and target valuations.

\footnotetext{
${ }^{23}$ Given that we do not impose a size restriction on our sample firms, using assets from Compustat as a measure of size would reduce our sample substantially.

${ }^{24}$ The marginal effects of the interaction terms are corrected to account for problems with interaction effects in nonlinear models as discussed by Ai and Norton (2003).
} 


\section{Analyst Recommendations and Post-Resolution Stock Performance}

Our evidence suggests that PMARs affect the merger process at least in part through their impact on a target's perception of a deal's value. This could indicate that PMARs represent informative signals about the values of the merger parties. Alternatively, it is possible PMARs do not contain information even though the market responds as though they do. This would add to evidence that merger decisions are driven in part by movements in valuations unrelated to firm fundamentals (Rhodes-Kropf et al., 2005; Edmans et al., 2012). We assess the information content of PMARs by examining medium- to long-run stock returns after a deal is completed or terminated. We focus on the post-resolution period to remove the effects of the decision to complete or terminate a merger itself from returns.

The predicted relation between the favorability of PMARs and post-resolution returns depends on whether the market impounds these recommendations into stock prices preresolution. If it does, we should observe no relation between PMAR favorability and post-merger returns. If it does not and these recommendations are informative, then stocks of firms with favorable PMARs should outperform those of firms with unfavorable PMARs. However, if the market overestimates the information contained in PMARs, then we should observe lower longrun returns in firms with favorable PMARs than in those with unfavorable ones.

We calculate the average favorability of PMARs for a merger as follows. Using the $\mathrm{I} / \mathrm{B} / \mathrm{E} / \mathrm{S}$ recommendation values (detailed in Section II.B), we average the numerical values of all recommendations issued between the announcement of the merger and its resolution for the acquirer and target separately. We characterize the average recommendation as favorable if it is greater than a 'buy' (the numerical average is $<2$ ) and unfavorable if it is less than or equal to a 'buy' (the numerical average is $\geq 2$ ). 
We implement two approaches in computing long-run abnormal returns post-merger resolution. The first is a calendar-time based approach advocated by Fama (1988) and developed formally by Mitchell and Stafford (2000). This involves, in each month, constructing an equalor value-weighted portfolio of all firms experiencing an event in the past $n$ months, where $n$ is the number of months over which we measure abnormal returns. We then capture the intercept (alpha) from a regression of the abnormal returns of each month's portfolio on the Fama and French (1993) factors, Mkt, SMB, and HML. This approach accounts for cross-sectional correlation in returns in overlapping periods for different firms experiencing an event.

The second approach is to compute buy-and-hold returns (BHARs) by calculating each firm's return over a period after a deal relative to returns over the same window for a benchmark set of firms (Lyon, Barber, and Tsai, 1999). While some argue BHARs do not account for crosssectional correlations in returns, this method is still commonly-used (Fu, Lin, and Officer, 2013; Savor and Lu, 2009); Bessembinder and Zhang (2013) argue differences in the two methods are based on control firms selected. We present results from tests using value-weighted calendartime abnormal returns, though we obtain similar results using BHARs.

We compute calendar-time portfolio abnormal returns for firms involved in mergers with favorable and unfavorable average recommendations separately over three month, six month, one year, and two year horizons post-merger resolution. Returns are calculated for acquirers for all deals, as well as completed and terminated mergers separately. We also examine targets in terminated deals (as a target's stock ceases to trade after a completed transaction). Table $\mathrm{X}$ details long-run abnormal returns for each group over each of the four post-event horizons.

Insert Table $\mathrm{X}$ here 
Over all four horizons, acquirers with favorable (unfavorable) average PMARs earn negative (positive) abnormal returns. While these returns are small and indistinguishable from zero over three- and six-months, one and two year returns are large and statistically significant. Acquirers with favorable average PMARs earn abnormal returns $10.19 \%$ and $14.53 \%$ lower than those of acquirers with unfavorable ones over one- and two-year post-resolution horizons, respectively. These differences are both statistically significant at the $1 \%$ level and are similar in completed deals. Differences in abnormal returns for targets with favorable and unfavorable average PMARs are small and statistically indistinguishable from zero over all horizons. We note the small sample size (460 terminations) limits the power of these tests. ${ }^{25}$

Overall, the results in this section, combined with returns around PMARs, indicate that investors overreact to PMARs. This suggests that the effect of PMARs on merger outcomes represents firms and/or shareholders reacting to valuation effects that are systematically biased.

\section{Conclusion}

This paper investigates the effect of stock analyst recommendations issued after merger announcements on completion decisions. Results based on a sample of U.S. public deals between 1993 and 2008 suggest recommendations impact deal outcomes by altering a target's assessment of the acquirer's and target's valuations, and hence the desirability of the offer. The probability of deal completion substantially increases (decreases) with the number of favorable acquirer (target) PMARs and decreases (increases) with the number of unfavorable acquirer (target)

\footnotetext{
${ }^{25}$ Using BHARs, the differences between abnormal post-resolution returns of acquirers with favorable and unfavorable average PMARs are $1.25 \%, 2.80 \%, 5.50 \%$, and $7.35 \%$ over three-month, six-month, one-year, and twoyear horizons, respectively. The difference over the three-month horizon is statistically significant at the ten percent level while over the longer horizons, it is statistically significant at the one percent level. We also obtain similar results if we measure abnormal returns using BHARs with Fama-French industry adjustments (BHARFF), cumulative abnormal returns (CAR), and CARs with Fama-French industry adjustments (CARFF).
} 
PMARs. Using an instrumental variables approach, merger outcomes continue to be related to recommendation favorability, consistent with PMARs having a causal effect on deal outcomes.

In order to clarify the causal relations between PMARs and merger outcomes, we explore two possible explanations: feedback and valuation. Using three tests to differentiate between these two explanations, we collectively provide support for valuation rather than feedback in driving the relations we observe between PMARs and merger completion. We also find that the stock market overreacts to these recommendations, as acquirers with favorable PMARs significantly underperform acquirers with unfavorable PMARs over various horizons.

Although a number of papers have examined how markets respond to analysts' opinions, few have examined the real economic implications of these recommendations on the decisions of firms and managers. Our results suggest managers and/or shareholders account for valuation implications of analyst recommendations around mergers, and these recommendations impact deal completion. Potential biases in recommendations, however, lead to possible mispricings of acquirers and targets in these transactions. This hints at the possibility that shifts in value for reasons unrelated to fundamentals play a role in determining the outcomes of proposed mergers. 


\section{References}

Ai, C. and E. Norton, 2003, Interaction terms in logit and probit models, Economics Letters 80, 123-129.

Barber, B., R. Lehavy, M. McNichols, and B. Trueman, 2001. Can investors profit from the prophets? Consensus analyst recommendations and stock returns, Journal of Finance 56, 531564.

Bates, T., Chang, H., and L. Lindsey, 2012, Analysts and corporate liquidity policy, Working paper, Arizona State University.

Bessembinder, H. and F. Zhang, 2013, Firm characteristics and long-run stock returns after corporate events, Journal of Financial Economics 109, 83-102.

Betton, S., B. E. Eckbo, and K. Thorburn, 2008, Corporate takeovers, Handbook of Corporate Finance: Empirical Corporate Finance, Vol. 2, Ch. 15, 291-240, Elsevier/North-Holland Handbook of Finance Series.

Bond, P., I. Goldstein, and N. Prescott, 2010, Market-based corrective actions, Review of Financial Studies 23, 781-820.

Bradshaw, M., S. Richardson, and R. Sloan, 2006, The relation between corporate financing activities, analysts' forecasts, and stock returns, Journal of Accounting and Economics 42, 5385.

Chen, T., J. Harford, and C. Lin, 2014, Do analysts matter for governance? Evidence from natural experiments, Journal of Financial Economics, forthcoming.

Derrien, F. and A. Kecskes, 2013, The real effects of financial shocks: evidence from exogenous changes in analyst coverage, Journal of Financial Economics 108, 1407-1440.

Degeorge, F., F. Derrien, A. Kecskes, and S. Michenaud, 2013, Do analysts' preferences affect corporate policies?, Working paper, HEC Paris.

Doukas, J., C. Kim, and C. Pantzalis, 2008, Do analysts influence corporate financing and investment? Financial Management 37, 303-339.

Dunbar, C., C.-Y. Hwang, and K. Shastri, 1999, Underwriter analyst recommendations: Conflict or rush to judgment?, Working paper, University of Western Ontario.

Edmans, A., I. Goldstein, and W. Jiang, 2012, The real effects of financial markets: The impact of prices on takeovers, Journal of Finance 67, 933-971.

Fama, E., 1988, Market efficiency, long-term returns, and behavioral finance, Journal of Financial Economics 49, 283-306.

Fama, E. and K. French, 1993, Common risk factors in the returns on stocks and bonds, Journal of Financial Economics 33, 3-56.

Fu, F., L. Lin, and M. Officer, 2013, Acquisitions driven by stock overvaluation: Are they good deals?, Journal of Financial Economics 109, 24-39.

He, J. and X. Tian, 2013, The dark side of analyst coverage: the case of innovation, Journal of Financial Economics 109, 856-878.

Kadan, O., L. Madureira, R. Wang, and T. Zach, 2009. Conflicts of interest and stock recommendations: effects of the Global Settlement and related regulations, Review of Financial Studies 22, 4189-4217. 
Loh, R. and R. Stulz, 2011, When are analyst recommendation changes influential?, Review of Financial Studies 24, 593-627.

Lyon, J., B. Barber, and C. Tsai, 1999. Improved methods for tests of long-run abnormal stock returns. Journal of Finance 54, 165-201.

Malmendier, M., M. Opp, and F. Saidi, 2012. Cash is king: revaluation of targets after merger bids, NBER working paper.

McLauglin, R., 1992, Does the form of compensation matter? Investment banker fee contracts in tender offers, Journal of Financial Economics 32, 223-260.

Mitchell, M. and E. Stafford, 2000, Managerial decisions and long-term stock price performance, Journal of Business 73, 287-329.

Moeller, S., F. Schlingemann, and R. Stulz, 2004, Firm size and gains from acquisitions, Journal of Financial Economics 73, 201-228.

Officer, M., 2003, Termination fees in mergers and acquisitions, Journal of Financial Economics 69, 431-467.

Rau, P.R., 2000. Investment bank market share, contingent fee payments and the performance of acquiring firms, Journal of Financial Economics 56, 293-324.

Rhodes-Kropf, M., D. Robinson, and S. Viswanathan, 2005, Valuation waves and merger activity: the empirical evidence, Journal of Financial Economics 77, 561-603.

Rhodes-Kropf, M. and S. Viswanathan, 2004, Market valuation and merger waves, Journal of Finance 59, 2685-2718.

Savor, P. and Q. Lu, 2009, Do stock mergers create value for acquirers?, Journal of Finance 64, 1061-1079.

Shleifer, A. and R. Vishny, 2003, Stock market driven acquisitions, Journal of Financial Economics 70, 295-311.

Stickel, S., 1995. The anatomy of the performance of buy and sell recommendations, Financial Analyst Journal 51, 25-39.

Stock, J. and M. Yogo, 2005, Testing for weak instruments in linear IV regression, Stock J, Yogo M. Testing for Weak Instruments in Linear IV Regression. In: Andrews DWK Identification and Inference for Econometric Models. New York: Cambridge University Press; 2005. pp. 80-108.

Womack, K., 1996, Do brokerage analyst recommendations have investment value?, Journal of Finance 51, 137-167. 


\section{Appendix A \\ Descriptions of Variables Used in Analyses}

\begin{tabular}{|c|c|}
\hline Variable & Description \\
\hline Favorable Acq Recs & Number of favorable acquirer PMARs (upgrades or strong buy initiations) \\
\hline Favorable Tgt Recs & Number of favorable target PMARs (upgrades or strong buy initiations) \\
\hline Unfavorable Acq Recs & Number of unfavorable acquirer PMARs (downgrades and initiations below buy) \\
\hline Unfavorable Tgt Recs & Number of unfavorable target PMARs (downgrades and initiations below buy) \\
\hline Number of Recs. in Pre-Ann. & Number of opinions in the pre-announcement period $(-50$ to -1$)$ \\
\hline Number of Recs. from Ann. & Number of opinions from day +1 to resolution \\
\hline Average Acq Rec & Average acquirer PMAR \\
\hline Average Tgt Rec & Average target PMAR \\
\hline Acquirer Advisors & Number of M\&A advisors to the acquirer \\
\hline Target Advisors & Number of M\&A advisors to the target \\
\hline Number Acq Analysts & Number of analysts making at least 1 acquirer PMAR in merger window \\
\hline Number Tgt Analysts & Number of analysts making at least 1 target PMAR in merger window \\
\hline $\begin{array}{l}\text { Same Analyst for Acquirer } \\
\text { and Target }\end{array}$ & $\begin{array}{l}\text { Indicator }=1 \text { if an analyst makes a recommendation on both the acquirer and target } \\
\text { on same day }\end{array}$ \\
\hline Acq (Tgt) Fee & Indicator $=1$ if a fee is paid to the acquirer (target) advisor \\
\hline Merger Program & Indicator $=1$ if acquirer makes 3 or more public deals over a 5 -year window \\
\hline Same 3-digit SIC & Indicator $=1$ if target and acquirer have the same 3 -digit SIC code \\
\hline Merger Completion & Indicator $=1$ if transaction is completed after announcement \\
\hline $100 \%$ Cash & Indicator $=1$ if transaction is a pure cash deal \\
\hline $100 \%$ Stock & Indicator $=1$ if transaction is a pure stock deal \\
\hline Tender Offer & Indicator $=1$ if transaction is a tender offer \\
\hline Cash Tender Offer & Indicator $=1$ if transaction is a cash tender offer \\
\hline Fixed Dollar Amount & Indicator $=1$ if transaction has a fixed dollar payment \\
\hline Fixed Exchange Ratio & Indicator $=1$ if number of shares exchanged between acquirer and target is fixed \\
\hline Fixed Payment Collar & Indicator $=1$ if transaction has a fixed payment collar \\
\hline Fixed Exchange Collar & Indicator $=1$ if transaction has a fixed exchange collar \\
\hline Collared Deal & Indicator $=1$ if transaction has any form of collared offer \\
\hline Bid Revisions & Indicator $=1$ if final price offered varies from initial offer price (SDC) \\
\hline Days to Resolution & Number of days from deal announcement to completion or termination \\
\hline Log Transaction Value & Natural log of value of the deal \\
\hline Absolute Size & Acquirer or target log market value of equity obtained from CRSP (Price*Shares) \\
\hline Relative Size & Absolute target size divided by sum of absolute target and acquirer size \\
\hline Premium & Offer price to target stock price premium 4 weeks prior to announcement (SDC) \\
\hline Acquirer Run-up & Pre-announcement returns for the acquirer ( -30 days to -5 days) \\
\hline Acquirer Ann Return & Announcement returns for the acquirer ( -1 day to +1 days) \\
\hline Target Run-up & Pre-announcement returns for the target ( -30 days to -5 days) \\
\hline Target Ann Return & Announcement returns for the target ( -1 day to +1 days) \\
\hline Industry Avg Rec & Industry consensus recommendation in the six months prior to the recommendation \\
\hline Analyst Avg Rec & $\begin{array}{l}\text { Average recommendation by the recommending analyst on her coverage universe } \\
\text { in the six months prior to the recommendation }\end{array}$ \\
\hline Broker Avg Rec & $\begin{array}{l}\text { Average recommendation at recommending analyst's brokerage firm excluding } \\
\text { acquirer and target industries in the six months prior to the recommendation }\end{array}$ \\
\hline
\end{tabular}




\section{Appendix B \\ Content of Analyst Reports on Acquirer and Targets}

This table provides a summary on the information provided in a sample of 300 randomlyselected acquirer and target analyst reports from Thomson One between 1999 and 2008. Panel A shows commonly delivered content in each report, while Panel B provides excerpts of anecdotal reports from four analysts on Veritas (target) which received a bid from Symantec Corp (acquirer) in 2004.

Panel A: Summary of Information in Analyst Reports

Content

Acquirer \% Target \%

Merger mentioned in report

$93 \% \quad 95 \%$

Specific discussion of synergies/fit

$80 \%$

$55 \%$

Merger explicitly discussed with respect to recommendation or

$57 \%$

$61 \%$

price target

Non-merger fundamentals discussed with respect to

$98 \%$

$65 \%$

recommendation or price target

Positive tone on transaction price

$15 \%$

$6 \%$

Negative tone on transaction price

$11 \%$

$1 \%$

Possibility of competing bids mentioned

$2 \%$

$3 \%$

Panel B: Veritas Reports

\begin{tabular}{|c|c|}
\hline JP Morgan & $\begin{array}{l}\text { We believe that it is hard to make a case for buying VRTS as stand-alone equity at current levels, which } \\
\text { now represents a premium to the group. We do not believe VRTS deserves a premium valuation given } \\
\text { slowing growth, recent miss-execution and structural changes in the marketplace that will make it harder for } \\
\text { VRTS to sustain growth longer term. We maintain our Neutral rating; however, there could be an } \\
\text { acquisition premium given the recent announcement. We do believe that VRTS has more value as an } \\
\text { acquisition, and while we would obviously expect to see a premium in an acquisition, we believe that } \\
\$ 29.70 \text { is probably on the inside of what VRTS could garner in a transaction. }\end{array}$ \\
\hline Fulcrum & $\begin{array}{l}\text { We are lowering our rating on VRTS to NEUTRAL (from BUY) primarily based on the stock's limited } \\
\text { upside from the current level. We believe the merger with Symantec will go through. Although there are } \\
\text { speculations of potential bidders with higher bids, we don't think speculation is a good reason for investors } \\
\text { to buy the stock at the current level. Although we fail to see significant product-synergy between VRTS and } \\
\text { SYMC, we would also see issues if a hardware vendor were to acquire VRTS - primarily being hardware } \\
\text { channel conflict. Also, VRTS stock is likely to move in-synch with SYMC stock going forward (1.1242 } \\
\text { share conversion); SYMC shares are down } 30 \% \text { this week, so we believe a rebound in SYMC stock could } \\
\text { move VRTS stock upward. However, again, the upside could be limited from the current level. }\end{array}$ \\
\hline CIBC & $\begin{array}{l}\text { "We are downgrading the shares of VERITAS from Sector Outperformer to Sector Performer... The } \\
\text { company has agreed to be bought by Symantec for roughly } \$ 13.5 \text { billion, or between } \$ 30-\$ 31 \text { per share, } \\
\text { which is just above our former target price of } \$ 30 \text {. Although there is a chance a competing bid could } \\
\text { emerge, we believe both the boards and management teams of both Symantec and VERITAS sound very } \\
\text { committed to this deal, giving any competing offer a low chance of success. Absent this, the only alternative } \\
\text { outcome, other than consummation, would be for the deal to break, which we believe would yield a } \\
\text { negative return for investors. }\end{array}$ \\
\hline Credit Suisse & $\begin{array}{l}\text { We are assuming coverage of VERITAS due to the departure of the previous lead analyst. Given the } \\
\text { pending merger with Symantec, we are assuming coverage with a Neutral rating and } \$ 28 \text { price target, as } \\
\text { compared with an Outperform rating and } \$ 25 \text { price target previously. }\end{array}$ \\
\hline
\end{tabular}


Table I

\section{Descriptive Statistics: Merger Sample}

The table provides descriptive data on the merger sample for our sample of public mergers that were announced and resolved between 1993 and 2008, excluding 2002 mergers. Merger variables, including method of payment, merger program, horizontal mergers, tender offers, cash tender offers, if a fixed dollar amount is set, bid revisions, collars, merger window, deal value, premium, and returns are presented. Hand-collected data on reasons for termination are also presented. Data are collected from SDC, SEC filings, as well as Factiva, Lexis-Nexis, and Dow Jones Newswire.

\begin{tabular}{llrrr}
\hline & & Full & Completed & Terminated \\
\hline $\mathrm{N}$ & Number of Mergers & 5,381 & 4,625 & 756 \\
& Pure Cash Financed & 1,310 & 1,172 & 138 \\
& Pure Stock Financed & 2,200 & 1,908 & 292 \\
& Tender Offers & 551 & 506 & 45 \\
& Cash Tender Offers & 387 & 361 & 26 \\
& Fixed Dollar Amount & 190 & 149 & 41 \\
& Bid Revisions & 260 & 218 & 42 \\
& Collared Deal & 431 & 404 & 27 \\
& Acquirer Merger Program & 2,060 & 1,857 & 203 \\
& Horizontal Mergers & 1,778 & 1,552 & 226 \\
\hline Termination & Acquirer & & & 168 \\
Reason & Target & & & 279 \\
& Regulatory & & & 76 \\
& Indeterminate & & & 219 \\
\hline Average & Days to Resolution & 130 & 132 & 116 \\
& Deal Value (in millions) & $\$ 1,153$ & $\$ 1,126$ & $\$ 1,352$ \\
& Premium & $45.01 \%$ & $45.82 \%$ & $37.51 \%$ \\
& Acquirer Run-up & $2.99 \%$ & $3.16 \%$ & $1.91 \%$ \\
& Target Run-up & $6.23 \%$ & $6.71 \%$ & $3.19 \%$ \\
& Acquirer Announcement Return & $-0.84 \%$ & $-0.76 \%$ & $-1.36 \%$ \\
& Target Announcement Return & $19.07 \%$ & $19.83 \%$ & $14.24 \%$ \\
\hline
\end{tabular}


Table II

Acquirer and Target PMARs and Returns

This table presents a summary of analyst recommendations and three-day cumulative abnormal returns for acquirers and targets. Panel A displays the recommendations returns and the total number of upgrades, reiterations, and downgrades (in parentheses) for acquirers and targets made prior to the merger announcement (-50 to -1 days) and following the merger announcement (the fifth day through resolution). Panel B provides the total number of strong buy, buy, and sell (including hold, sell, and strong sell initiations) for acquirers and targets over the same time periods as noted in Panel A. Recommendation data is collected from $\mathrm{I} / \mathrm{B} / \mathrm{E} / \mathrm{S}$, announcement and resolution dates are collected from SDC, and returns are collected from CRSP. ${ }^{* * *},{ }^{* *}$ and ${ }^{*}$ indicates significance at the $1 \%, 5 \%$, and $10 \%$ confidence levels, respectively.

\begin{tabular}{|c|c|c|c|c|c|c|}
\hline \multicolumn{7}{|c|}{ Panel A: Recommendation Revisions } \\
\hline & \multicolumn{3}{|c|}{ Acquirer } & \multicolumn{3}{|c|}{ Target } \\
\hline & Upgrade & Reiteration & Downgrade & Upgrade & Reiteration & Downgrade \\
\hline $\begin{array}{l}\text { Pre- } \\
\text { Announcement }\end{array}$ & $\begin{array}{c}2.09 \%{ }^{* * *} \\
(1,204)\end{array}$ & $\begin{array}{c}-0.01 \% \\
(465)\end{array}$ & $\begin{array}{c}-2.14 \%^{* * *} \\
(1,098)\end{array}$ & $\begin{array}{l}3.27 \%{ }^{* * *} \\
(519)\end{array}$ & $\begin{array}{l}0.74 \% \\
(209)\end{array}$ & $\begin{array}{c}-4.15 \%{ }^{* * * *} \\
(617)\end{array}$ \\
\hline $\begin{array}{l}\text { Post- } \\
\text { Announcement }\end{array}$ & $\begin{array}{c}1.51 \%{ }^{* * *} \\
(3,670)\end{array}$ & $\begin{array}{l}0.10 \% \\
(1,240)\end{array}$ & $\begin{array}{c}-2.89 \%^{* * *} \\
(3,398)\end{array}$ & $\begin{array}{c}0.55 \%{ }^{* * * *} \\
(813)\end{array}$ & $\begin{array}{c}-0.30 \% \\
(404)\end{array}$ & $\begin{array}{c}-0.60 \%{ }^{* * *} \\
(1,559)\end{array}$ \\
\hline \multicolumn{7}{|c|}{ Panel B: Recommendation Initiations } \\
\hline & \multicolumn{3}{|c|}{ Acquirer } & \multicolumn{3}{|c|}{ Target } \\
\hline & $\begin{array}{l}\text { Strong } \\
\text { Buy }\end{array}$ & Buy & Sell & $\begin{array}{l}\text { Strong } \\
\text { Buy }\end{array}$ & Buy & Sell \\
\hline $\begin{array}{l}\text { Pre- } \\
\text { Announcement }\end{array}$ & $\begin{array}{c}1.18 \% \text { *** } \\
(452)\end{array}$ & $\begin{array}{c}0.47 \% \\
(515)\end{array}$ & $\begin{array}{c}-0.30 \% \\
(475)\end{array}$ & $\begin{array}{c}2.50 \%{ }^{* * * *} \\
(161)\end{array}$ & $\begin{array}{l}5.88 \% \\
(204)\end{array}$ & $\begin{array}{c}-0.70 \% \\
(193)\end{array}$ \\
\hline $\begin{array}{l}\text { Post- } \\
\text { Announcement }\end{array}$ & $\begin{array}{c}1.12 \%{ }^{* * * *} \\
(1,128)\end{array}$ & $\begin{array}{c}0.08 \% \\
(1,302)\end{array}$ & $\begin{array}{c}-0.44 \% \%^{* * *} \\
(1,291)\end{array}$ & $\begin{array}{c}0.42 \% \\
(158)\end{array}$ & $\begin{array}{c}-0.07 \% \\
(185)\end{array}$ & $\begin{array}{c}-0.09 \% \\
(378)\end{array}$ \\
\hline
\end{tabular}


Table III

Modeling the Probability of Completion

This table presents marginal effects (in percentages) from logistic regressions on the probability of a merger completion. Predictors of merger completion include recommendation and analyst characteristics, merger characteristics, and indicator variables for M\&A advisory fees. Models 2 and 3 include variables for the number of advisors, log transaction value, method of payment, days to resolution, acquirer and target run-up and announcement returns, and an indicator and merger programs. Additional controls for total number of recommendations, the average recommendation level, same analyst for acquirer and target, collar type, and an indicator for horizontal mergers are included in the regressions (Models 2 and 3) but are suppressed for exposition. z-statistic p-values are reported and bold indicates significance of at least $10 \%$. Huber-White robust standard errors are used. Pseudo- $\mathrm{R}^{2} \mathrm{~s}$ are also provided for each model. Variables are defined in Appendix A.

\begin{tabular}{|c|c|c|c|c|c|c|}
\hline \multirow[b]{2}{*}{ Variable } & \multicolumn{2}{|c|}{ Model 1} & \multicolumn{2}{|c|}{ Model 2} & \multicolumn{2}{|c|}{ Model 3} \\
\hline & M.E. & $p-v a l$ & M.E. & $p$-val & M.E. & $p$-val \\
\hline Favorable Acq Recs & 1.09 & 0.01 & 0.98 & 0.01 & 0.94 & 0.01 \\
\hline Unfavorable Acq Recs & -1.95 & 0.00 & -1.38 & $\mathbf{0 . 0 0}$ & -1.41 & 0.00 \\
\hline Favorable Tgt Recs & -2.15 & 0.00 & -1.24 & 0.01 & -1.24 & 0.01 \\
\hline Unfavorable Tgt Recs & 1.60 & 0.00 & 0.32 & 0.39 & 0.26 & 0.48 \\
\hline Num Acq Analysts & 1.75 & 0.00 & 0.82 & 0.00 & 0.81 & 0.00 \\
\hline Num Tgt Analysts & -1.10 & 0.00 & -0.62 & 0.06 & -0.34 & 0.29 \\
\hline Acquirer Advisors & & & 2.82 & 0.00 & 0.06 & 0.96 \\
\hline Target Advisors & & & 8.02 & $\mathbf{0 . 0 0}$ & 1.51 & 0.15 \\
\hline Merger Program & & & 2.02 & 0.02 & 2.20 & 0.01 \\
\hline Days to Resolution & & & 0.01 & 0.07 & 0.01 & 0.14 \\
\hline Log Transaction Value & & & -1.65 & 0.00 & -1.90 & 0.00 \\
\hline $100 \%$ Cash & & & -0.21 & 0.86 & 0.27 & 0.83 \\
\hline Cash Tender Offer & & & 3.80 & 0.00 & 3.13 & 0.01 \\
\hline $100 \%$ Stock & & & 0.84 & 0.35 & 0.74 & 0.42 \\
\hline Acq Run-up & & & 3.34 & 0.11 & 3.97 & 0.07 \\
\hline Acq Ann Return & & & 6.49 & 0.08 & 7.76 & 0.04 \\
\hline Tgt Run-up & & & 5.28 & 0.00 & 5.04 & 0.00 \\
\hline Tgt Ann Return & & & 3.09 & 0.07 & 2.50 & 0.14 \\
\hline Acq Fee & & & & & 4.55 & 0.02 \\
\hline Tgt Fee & & & & & 18.44 & 0.00 \\
\hline Additional Controls & & No & & Yes & & Yes \\
\hline Year Fixed Effects & & Yes & & Yes & & Yes \\
\hline Industry Fixed Effects & & Yes & & Yes & & Yes \\
\hline Observations & & 5,381 & & 3,596 & & 3,596 \\
\hline Pseudo- $\mathrm{R}^{2}$ & & 0.09 & & 0.19 & & 0.21 \\
\hline
\end{tabular}


Table IV

\section{Modeling the Probability of Completion: Instrumental Variable Approach}

This table presents marginal effects (in percentages) from logistic regressions on the probability of a merger completion. First stage regressions model acquirer or target upgrades using three instrumental variables (Panel A). The first is the average recommendation level in the industry (IA) of either the acquirer or target, the second is the average recommendation level for the predicting analyst (AA) for either the acquirer or target, and the third is the average recommendation level for the brokerage house of the recommending analyst excluding all firms covered by the analyst or in the same industry as the acquirer or target (BA). In Panel B, only the BA instrument is used. Fitted values from logistic regressions where the instruments are ALL (Panel A: IA, AA, and BA) or BA (Panel B) are then used in second stage regressions. Independent variables are the same as those reported in Table III, Model 3, although the number of days to resolution is not included in first stage regressions since it is not known at the time the recommendation revision is made. p-values are reported and bold indicates significance of at least $10 \%$. HuberWhite robust standard errors are used. Pseudo- $\mathrm{R}^{2} \mathrm{~s}$ are also provided for each model. Variables are defined in Appendix A.

Panel A: Analyst, Industry, and Brokerage Instruments

\begin{tabular}{lrrrrrr}
\hline & \multicolumn{2}{c}{$\begin{array}{c}\text { Acq } \mathbf{1}^{\text {st }} \text { Stg } \\
\text { IV-ALL }\end{array}$} & \multicolumn{2}{c}{ Tgt 1 $\mathbf{1}^{\text {st }}$ Stg } & \multicolumn{2}{c}{ Model 1 } \\
& IV -AL & \multicolumn{2}{c}{ IV-ALL } \\
\hline Variable & $\boldsymbol{p}$-val & Est & p-val & M.E. & p-val \\
\hline Fav Acq Recs Fitted & & & & & 1.00 & $\mathbf{0 . 0 6}$ \\
Fav Tgt Recs Fitted & & & & & -0.74 & $\mathbf{0 . 0 6}$ \\
Num Acq Analysts & -0.23 & 0.28 & -0.22 & $\mathbf{0 . 0 8}$ & 0.17 & 0.31 \\
Num Tgt Analysts & 0.12 & 0.62 & 1.16 & $\mathbf{0 . 0 0}$ & -0.35 & 0.13 \\
Acquirer Advisors & 0.10 & 0.95 & -1.60 & 0.16 & -0.57 & 0.64 \\
Target Advisors & 3.46 & $\mathbf{0 . 0 4}$ & 0.85 & 0.48 & 1.76 & 0.19 \\
Merger Program & 0.61 & 0.68 & -1.79 & 0.15 & 2.13 & 0.12 \\
Days to Resolution & & & & & -0.02 & $\mathbf{0 . 0 0}$ \\
Log Transaction Value & 0.89 & 0.14 & 1.76 & $\mathbf{0 . 0 0}$ & -0.90 & $\mathbf{0 . 1 0}$ \\
100\% Cash & -1.49 & 0.53 & -2.84 & 0.15 & -0.55 & 0.82 \\
Cash Tender Offer & 1.91 & 0.56 & -1.75 & 0.54 & -2.25 & 0.60 \\
100\% Stock & 1.50 & 0.37 & 0.68 & 0.63 & -1.74 & 0.25 \\
Acquirer Run-up & -5.89 & 0.22 & 4.96 & 0.24 & 9.94 & $\mathbf{0 . 0 1}$ \\
Acq Ann Return & 13.37 & 0.15 & 12.96 & $\mathbf{0 . 0 8}$ & 4.64 & 0.48 \\
Target Run-up & -1.06 & 0.76 & -5.80 & $\mathbf{0 . 0 9}$ & 4.68 & 0.11 \\
Target Ann Return & -0.98 & 0.76 & -6.83 & $\mathbf{0 . 0 3}$ & 3.71 & 0.25 \\
Acquirer Fee & -0.45 & 0.86 & 0.88 & 0.70 & -0.28 & 0.90 \\
Target Fee & -2.24 & 0.55 & -8.74 & $\mathbf{0 . 0 2}$ & 27.47 & $\mathbf{0 . 0 8}$ \\
Industry Avg Rec (IA) & 8.95 & $\mathbf{0 . 0 5}$ & 1.63 & 0.60 & & \\
Analyst Avg Rec (AA) & 15.41 & $\mathbf{0 . 0 0}$ & 4.46 & $\mathbf{0 . 0 0}$ & & \\
Broker Avg Rec (BA) & 1.10 & 0.67 & 4.55 & $\mathbf{0 . 0 2}$ & & \\
Additional Controls & & Yes & & Yes & & Yes \\
Year Fixed Effects & & Yes & & Yes & & Yes \\
Observations & 11,969 & & 4,980 & & 3,275 \\
Stock-Yogo F-test & & 0.00 & & 0.00 & & \\
Pseudo-R ${ }^{2}$ & & 0.10 & & 0.12 & & 0.20 \\
\hline & & & & & &
\end{tabular}


Panel B: Brokerage Instrument Only

\begin{tabular}{lrrrrrr}
\hline & \multicolumn{1}{c}{$\begin{array}{c}\text { Acq } \\
\text { IV-BA }\end{array}$} & \multicolumn{2}{c}{$\begin{array}{c}\text { stg } \\
\text { IV-BA }\end{array}$} & \multicolumn{2}{c}{$\begin{array}{c}\text { Model 1 } \\
\text { IV-BA }\end{array}$} \\
\hline Variable & Est & $\boldsymbol{p}$-val & Est & p-val & M.E. & p-val \\
\hline Fav Acq Recs Fitted & & & & & 0.96 & $\mathbf{0 . 0 7}$ \\
Fav Tgt Recs Fitted & & & & & -0.68 & $\mathbf{0 . 0 8}$ \\
Num Acq Analysts & -0.20 & 0.35 & -0.20 & $\mathbf{0 . 1 0}$ & 0.19 & 0.26 \\
Num Tgt Analysts & 0.10 & 0.67 & 1.08 & $\mathbf{0 . 0 0}$ & -0.35 & 0.12 \\
Acquirer Advisors & -0.05 & 0.98 & -1.27 & 0.24 & -0.05 & 0.97 \\
Target Advisors & 0.03 & $\mathbf{0 . 0 6}$ & -0.13 & 0.91 & 1.67 & 0.20 \\
Merger Program & -0.83 & 0.57 & -1.63 & 0.18 & 2.90 & $\mathbf{0 . 0 4}$ \\
Days to Resolution & & & & & -0.02 & $\mathbf{0 . 0 0}$ \\
Log Transaction Value & 0.89 & 0.13 & 1.89 & $\mathbf{0 . 0 0}$ & -1.16 & $\mathbf{0 . 0 3}$ \\
100\% Cash & -1.51 & 0.51 & -2.82 & 0.15 & -1.09 & 0.66 \\
Cash Tender Offer & 2.89 & 0.37 & -2.06 & 0.46 & -0.65 & 0.84 \\
100\% Stock & 1.85 & 0.26 & 0.33 & 0.81 & -1.42 & 0.34 \\
Acquirer Run-up & -7.58 & 0.11 & 6.61 & 0.11 & 12.01 & $\mathbf{0 . 0 0}$ \\
Acq Ann Return & 15.42 & $\mathbf{0 . 0 9}$ & 13.55 & $\mathbf{0 . 0 6}$ & 4.76 & 0.46 \\
Target Run-up & -1.17 & 0.73 & -6.57 & $\mathbf{0 . 0 5}$ & 5.18 & $\mathbf{0 . 0 8}$ \\
Target Ann Return & -1.65 & 0.60 & -8.00 & $\mathbf{0 . 0 1}$ & 3.48 & 0.27 \\
Acquirer Fee & -0.18 & 0.95 & 0.60 & 0.79 & 0.33 & 0.89 \\
Target Fee & -1.47 & 0.69 & -6.21 & $\mathbf{0 . 0 9}$ & 26.48 & $\mathbf{0 . 0 8}$ \\
Broker Avg Rec (BA) & 9.74 & $\mathbf{0 . 0 0}$ & 1.24 & 0.48 & & \\
Additional Controls & & Yes & & Yes & & Yes \\
Year Fixed Effects & & Yes & & Yes & & Yes \\
Observations & 11,969 & & 4,980 & & 3,275 \\
Stock-Yogo F-test & & 0.05 & & 0.01 & & \\
Pseudo-R & & 0.09 & & 0.11 & & 0.21 \\
\hline & & & & & &
\end{tabular}


Table V

\section{Feedback and Valuation Explanation Predictions}

This table describes the effects of favorable and unfavorable acquirer and target PMARs predicted by the feedback and valuation explanations. For the probability of completion (Table III), we examine the predictions based on both explanations from both the acquirer's and target's standpoint. For the remainder of the tests, we focus on acquirerdriven feedback and target-driven valuation explanations.

\begin{tabular}{|c|c|c|c|c|c|c|c|c|}
\hline \multicolumn{4}{|c|}{ Feedback } & & \multicolumn{4}{|c|}{ Valuation } \\
\hline \multicolumn{2}{|c|}{ Acquirer } & \multicolumn{2}{|c|}{ Target } & & \multicolumn{2}{|c|}{ Acquirer } & \multicolumn{2}{|c|}{ Target } \\
\hline$F a v$ & Unfav & $F a v$ & Unfav & & Fav & Unfav & $F a v$ & Unfav \\
\hline Pos & Neg & Pos & Neg & $\begin{array}{c}\text { Probability of Completion } \\
\text { (Table III) } \\
\text { Acquirer PMAR } \\
\text { Target PMAR }\end{array}$ & $\begin{array}{l}\text { Neg } \\
\text { Pos }\end{array}$ & $\begin{array}{l}\text { Pos } \\
\text { Neg }\end{array}$ & $\begin{array}{l}\text { Pos } \\
\text { Neg }\end{array}$ & $\begin{array}{l}\text { Neg } \\
\text { Pos }\end{array}$ \\
\hline Neg & Pos & & & $\begin{array}{c}\text { Determinants of Termination* } \\
\text { (Table VI) } \\
\text { Acquirer Terminates } \\
\text { Acquirer PMAR } \\
\text { Target PMAR }\end{array}$ & & & & \\
\hline & & & & $\begin{array}{c}\text { Target Terminates } \\
\text { Acquirer PMAR } \\
\text { Target PMAR }\end{array}$ & & & $\begin{array}{l}\text { Neg } \\
\text { Pos }\end{array}$ & $\begin{array}{l}\text { Pos } \\
\text { Neg }\end{array}$ \\
\hline & & & & $\begin{array}{c}\text { Method of Payment } \\
\text { (Table VII) } \\
\text { Stock Merger }\end{array}$ & & & & \\
\hline Pos & Neg & & & $\begin{array}{c}\text { Acquirer PMAR } \\
\text { Target PMAR }\end{array}$ & & & $\begin{array}{l}\text { Pos } \\
\text { Neg }\end{array}$ & $\begin{array}{l}\text { Neg } \\
\text { Pos }\end{array}$ \\
\hline Pos & Neg & & & $\begin{array}{l}\text { Cash Merger } \\
\text { Acquirer PMAR } \\
\text { Target PMAR }\end{array}$ & & & Neg & Pos \\
\hline Pos & Neg & & & $\begin{array}{c}\text { Relative Target Size } \\
\text { (Table IX) } \\
\text { Acquirer PMAR } \\
\text { Target PMAR }\end{array}$ & & & & \\
\hline
\end{tabular}

* Prediction of termination rather than completion 
Table VI

\section{Modeling Who Terminates}

This table presents marginal effects (in percentages) from multinomial logistic regressions on the probability of which party terminates an announced merger. The base case is completion. Predictors of merger termination include recommendation and analyst characteristics, merger characteristics, and indicator variables for M\&A advisory fees and are similar to those presented in previous tables. Z-statistic p-values are reported and bold indicates significance of at least $10 \%$. Huber-White robust standard errors are used. Pseudo- $\mathrm{R}^{2}$ s are also provided for each model. Variables are defined in Appendix A.

\begin{tabular}{lrrrr}
\hline & \multicolumn{2}{c}{$\begin{array}{c}\text { Acquirer } \\
\text { Terminates }\end{array}$} & $\begin{array}{c}\text { Target } \\
\text { Terminates }\end{array}$ \\
\hline Variable & M.E. & p-val & M.E. & p-val \\
\hline Favorable Acq Recs & -0.10 & 0.11 & -0.33 & $\mathbf{0 . 0 7}$ \\
Unfavorable Acq Recs & 0.03 & 0.59 & 0.48 & $\mathbf{0 . 0 0}$ \\
Favorable Tgt Recs & -0.01 & 0.92 & 0.28 & 0.18 \\
Unfavorable Tgt Recs & -0.08 & 0.19 & -0.08 & 0.58 \\
Num Acq Analysts & -0.03 & 0.44 & -0.39 & $\mathbf{0 . 0 0}$ \\
Num Tgt Analysts & 0.06 & 0.20 & 0.11 & 0.37 \\
Acquirer Advisors & 0.02 & 0.91 & 0.08 & 0.84 \\
Target Advisors & 0.14 & 0.27 & -0.74 & $\mathbf{0 . 1 0}$ \\
Merger Program & -0.33 & $\mathbf{0 . 0 2}$ & 0.03 & 0.95 \\
Days to Resolution & 0.00 & $\mathbf{0 . 0 8}$ & 0.00 & $\mathbf{0 . 0 5}$ \\
Log Transaction Value & 0.16 & $\mathbf{0 . 0 0}$ & 0.72 & $\mathbf{0 . 0 0}$ \\
Acquirer Run-up & -0.40 & 0.22 & -1.10 & 0.19 \\
Acq Ann Return & -1.14 & $\mathbf{0 . 0 6}$ & -0.17 & 0.88 \\
Target Run-up & -0.62 & $\mathbf{0 . 0 1}$ & -1.55 & $\mathbf{0 . 0 2}$ \\
Target Ann Return & -0.08 & 0.74 & -0.48 & 0.44 \\
Acquirer Fee & -0.48 & $\mathbf{0 . 0 7}$ & -2.17 & $\mathbf{0 . 0 1}$ \\
Target Fee & -2.45 & $\mathbf{0 . 0 0}$ & -4.69 & $\mathbf{0 . 0 0}$ \\
Additional Controls & & Yes & & Yes \\
Year Fixed Effects & & Yes & & Yes \\
Industry Fixed Effects & & Yes & & Yes \\
Observations & & & & 0.437 \\
Pseudo-R & & & &
\end{tabular}


Table VII

Modeling the Probability of Completion: Cash vs. Stock Mergers

This table presents marginal effects (in percentages) from logistic regressions on the probability of a merger completion by method of payment. Predictors of merger completion include recommendations and analyst characteristics, as well as variables for the number of advisors, log transaction value, days to resolution, acquirer and target run-up and announcement returns, and an indicator and merger programs. Additional controls for total number of recommendations, the average recommendation level, same analyst for acquirer and target, collar type, and an indicator for horizontal mergers are included in the regressions but are suppressed for exposition. z-statistic pvalues are reported and bold indicates significance of at least 10\%. Huber-White robust standard errors are used. Pseudo- $\mathrm{R}^{2} \mathrm{~s}$ are also provided for each model. Independent variables are defined in Appendix A.

\begin{tabular}{lrcrc}
\hline & \multicolumn{2}{c}{ Stock } & \multicolumn{2}{c}{ Pure Cash } \\
\hline Variable & M.E. & p-val & M.E. & p-val \\
\hline Favorable Acq Recs & 1.25 & $\mathbf{0 . 0 0}$ & -0.21 & 0.75 \\
Unfavorable Acq Recs & -1.38 & $\mathbf{0 . 0 0}$ & -0.27 & 0.62 \\
Favorable Tgt Recs & -1.59 & $\mathbf{0 . 0 1}$ & -0.75 & 0.45 \\
Unfavorable Tgt Recs & 0.20 & 0.66 & 0.95 & 0.14 \\
Num Acq Analysts & 0.50 & $\mathbf{0 . 0 9}$ & 1.38 & $\mathbf{0 . 0 0}$ \\
Num Tgt Analysts & -0.48 & 0.21 & -0.18 & 0.72 \\
Acquirer Advisors & 0.06 & 0.96 & -0.95 & 0.57 \\
Target Advisors & 2.41 & $\mathbf{0 . 0 5}$ & -1.65 & 0.26 \\
Merger Program & 2.27 & $\mathbf{0 . 0 3}$ & 1.49 & 0.20 \\
Days to Resolution & 0.01 & $\mathbf{0 . 0 1}$ & -0.01 & $\mathbf{0 . 0 8}$ \\
Log Transaction Value & -1.45 & $\mathbf{0 . 0 0}$ & -1.75 & $\mathbf{0 . 0 0}$ \\
Acquirer Run-up & 3.73 & 0.12 & 3.07 & 0.37 \\
Acq Ann Return & 10.89 & $\mathbf{0 . 0 2}$ & -4.77 & 0.40 \\
Target Run-up & 6.02 & $\mathbf{0 . 0 0}$ & 0.07 & 0.97 \\
Target Ann Return & 3.47 & $\mathbf{0 . 1 0}$ & 1.17 & 0.54 \\
Acquirer Fee & 5.27 & $\mathbf{0 . 0 2}$ & 3.25 & 0.22 \\
Target Fee & 16.64 & $\mathbf{0 . 0 0}$ & 35.15 & $\mathbf{0 . 0 0}$ \\
Additional Controls & & Yes & & Yes \\
Year Fixed Effects & & Yes & & Yes \\
Industry Fixed Effects & & Yes & & Yes \\
Observations & & 2,695 & & 0.30 \\
Pseudo-R & & 0.22 & & \\
\hline
\end{tabular}




\section{Instrumental Variables and Modeling Who Terminates: Stock Deals Only}

This table presents marginal effects (in percentages) from logistic regressions on the probability of a merger completion using three instrumental variables detailed in Table IV (Model 1). Fitted values from logistic regressions are used to capture acquirer and target recommendation favorability and independent variables are the same as those reported in Table IV. Columns 2 and 3 present marginal effects (in percentages) from multinomial logistic regressions on the probability of which party terminates an announced merger. Predictors of merger termination are similar to those presented in previous tables. Only deals in which at least some stock is used as a method of payment are included in this table. z-statistic p-values are reported and bold indicates significance of at least $10 \%$. Huber-White robust standard errors are used. Pseudo- $\mathrm{R}^{2} \mathrm{~s}$ are also provided for each model. Variables are defined in Appendix A.

\begin{tabular}{|c|c|c|c|c|c|c|}
\hline \multirow[b]{2}{*}{ Variable } & \multicolumn{2}{|c|}{$\begin{array}{c}\text { IV-ALL } \\
\text { Completion }\end{array}$} & \multicolumn{2}{|c|}{$\begin{array}{c}\text { Acquirer } \\
\text { Terminates }\end{array}$} & \multicolumn{2}{|c|}{$\begin{array}{c}\text { Target } \\
\text { Terminates }\end{array}$} \\
\hline & M.E. & $p$-val & M.E. & $p$-val & M.E. & $p$-val \\
\hline Fav Acq Recs Fitted & 1.35 & 0.08 & & & & \\
\hline Fav Tgt Recs Fitted & -0.93 & 0.06 & & & & \\
\hline Favorable Acq Recs & & & -0.12 & 0.11 & -0.68 & 0.01 \\
\hline Unfavorable Acq Recs & & & -0.06 & 0.36 & 0.34 & 0.06 \\
\hline Favorable Tgt Recs & & & -0.05 & 0.65 & 0.08 & 0.79 \\
\hline Unfavorable Tgt Recs & & & -0.18 & 0.04 & -0.24 & 0.24 \\
\hline Num Acq Analysts & 0.20 & 0.36 & 0.03 & 0.57 & -0.36 & 0.01 \\
\hline Num Tgt Analysts & -0.51 & 0.08 & 0.10 & 0.08 & 0.26 & 0.10 \\
\hline Acquirer Advisors & 0.53 & 0.75 & -0.08 & 0.67 & 0.12 & 0.81 \\
\hline Target Advisors & 2.94 & 0.10 & 0.08 & 0.65 & -1.12 & 0.08 \\
\hline Merger Program & 2.09 & 0.21 & -0.23 & 0.16 & -0.29 & 0.49 \\
\hline Days to Resolution & -0.02 & $\mathbf{0 . 0 3}$ & 0.00 & 0.44 & -0.01 & 0.01 \\
\hline Log Transaction Value & -1.11 & 0.11 & 0.14 & 0.01 & 0.49 & $\mathbf{0 . 0 0}$ \\
\hline Acquirer Run-up & 13.56 & 0.01 & -0.07 & 0.86 & -0.64 & 0.55 \\
\hline Acq Ann Return & 4.55 & 0.56 & -0.10 & 0.22 & -0.02 & 0.93 \\
\hline Target Run-up & 4.58 & 0.22 & -1.01 & 0.00 & -1.96 & 0.02 \\
\hline Target Ann Retı & 3.72 & 0.37 & -0.08 & 0.29 & -0.28 & 0.17 \\
\hline Acquirer Fee & 1.37 & 0.70 & -0.36 & 0.24 & -2.84 & 0.01 \\
\hline Target Fee & 19.75 & 0.21 & -2.25 & 0.00 & -3.65 & 0.01 \\
\hline Additional C & & Yes & & Yes & & $\mathrm{Ye}$ \\
\hline Industry Fixed Effects & & No & & Yes & & Yes \\
\hline Year Fixed Effects & & Yes & & Yes & & Yes \\
\hline Observatic & & 2,695 & & & & 2,551 \\
\hline Pseudo- $\mathrm{R}^{2}$ & & 0.19 & & & & 0.20 \\
\hline
\end{tabular}


Table IX

Modeling the Probability of Completion: Relative and Absolute Target Size

This table presents marginal effects (in percentages) logistic regressions on the probability of a merger completion by relative target size (target market value of equity scaled by the sum of the target and acquirer market value of equity) controlling for the target absolute size. Relative and absolute size measures are interacted with acquirer and target PMAR favorability variables and analyst coverage. Models $1-3$ replicate those presented in Table III and include recommendations and analyst characteristics, as well as variables for the number of advisors, total number of recommendations, the average recommendation level, same analyst for acquirer and target, collar type, log transaction value, days to resolution, acquirer and target run-up and announcement returns, and indicators for horizontal mergers, merger programs, acquirer fees and target fees but are suppressed for exposition. Further each model includes the relative and absolute size measures as additional controls. z-statistic p-values are reported and bold indicates significance of at least $10 \%$. Huber-White robust standard errors are used. Pseudo- $\mathrm{R}^{2} \mathrm{~s}$ are also provided for each model. Variables are defined in Appendix A.

\begin{tabular}{lrrrrrr}
\hline & \multicolumn{2}{c}{ Model 1 } & Model 2 & \multicolumn{2}{c}{ Model 3 } \\
\hline Variable & M.E. & p-val & M.E. & p-val & M.E. & p-val \\
\hline Favorable Acq Recs & -0.15 & 0.93 & -1.16 & 0.37 & -1.40 & 0.26 \\
Unfavorable Acq Recs & -1.25 & 0.33 & -1.94 & $\mathbf{0 . 0 6}$ & -2.10 & $\mathbf{0 . 0 3}$ \\
Favorable Tgt Recs & -9.72 & $\mathbf{0 . 0 0}$ & -4.58 & $\mathbf{0 . 0 6}$ & -3.94 & $\mathbf{0 . 0 9}$ \\
Unfavorable Tgt Recs & 4.07 & $\mathbf{0 . 0 8}$ & 4.03 & $\mathbf{0 . 0 3}$ & 3.90 & $\mathbf{0 . 0 4}$ \\
Num Acq Analysts & 2.18 & $\mathbf{0 . 0 1}$ & 3.50 & $\mathbf{0 . 0 0}$ & 3.50 & $\mathbf{0 . 0 0}$ \\
Num Tgt Analysts & 0.89 & 0.57 & -2.88 & $\mathbf{0 . 0 4}$ & -3.34 & $\mathbf{0 . 0 1}$ \\
& & & & & & \\
Favorable Acq Recs*Rel Size & -2.49 & 0.33 & -2.43 & 0.18 & -2.91 & 0.11 \\
Unfavorable Acq Recs*Rel Size & -3.61 & $\mathbf{0 . 0 9}$ & -1.96 & 0.19 & -1.58 & 0.29 \\
Favorable Tgt Recs*Rel Size & 5.37 & $\mathbf{0 . 0 7}$ & 3.23 & 0.16 & 2.66 & 0.24 \\
Unfavorable Tgt Recs*Rel Size & -2.29 & 0.27 & 0.07 & 0.96 & 0.78 & 0.61 \\
Num Acq Analysts*Rel Size & 1.81 & 0.16 & 1.11 & 0.26 & 1.15 & 0.25 \\
Num Tgt Analysts* Rel Size & 0.59 & 0.68 & -0.93 & 0.43 & -1.32 & 0.26 \\
Favorable Acq Recs*Abs Size & 0.37 & 0.14 & 0.43 & $\mathbf{0 . 0 3}$ & 0.46 & $\mathbf{0 . 0 2}$ \\
Unfavorable Acq Recs*Abs Size & 0.12 & 0.60 & 0.35 & 0.22 & 0.21 & 0.20 \\
Favorable Tgt Recs*Abs Size & 0.80 & $\mathbf{0 . 0 2}$ & 0.20 & 0.23 & 0.28 & 0.31 \\
Unfavorable Tgt Recs*Abs Size & -0.28 & 0.33 & -0.49 & $\mathbf{0 . 0 4}$ & -0.50 & $\mathbf{0 . 0 3}$ \\
Num Acq Analysts*Abs Size & -0.32 & $\mathbf{0 . 0 2}$ & -0.51 & $\mathbf{0 . 0 0}$ & -0.51 & $\mathbf{0 . 0 0}$ \\
Num Tgt Analysts*Abs Size & -0.18 & 0.36 & 0.40 & $\mathbf{0 . 0 2}$ & 0.49 & $\mathbf{0 . 0 1}$ \\
Additional Controls & & No & & Yes & & Yes \\
Year Fixed Effects & & Yes & & Yes & & Yes \\
Industry Fixed Effects & & Yes & & Yes & & Yes \\
Observations & & 2,743 & & 2,743 & & 2,743 \\
Pseudo-R ${ }^{2}$ & 0.13 & & 0.21 & & 0.24 \\
\hline & & & & &
\end{tabular}


Table X

\section{Post-Resolution Performance}

This table examines whether analysts, through their recommendations, have the ability to predict post-resolution performance. Post-resolution returns are measured as calendar-time portfolio abnormal returns using the methodology presented in Mitchell and Stafford (2000) for three months, six months, one year and two years following the resolution (either completion or termination) of the merger. Recommendations are averaged across analysts and are delineated into favorable (values less than two) and unfavorable recommendations (values greater than two). Acquirers and targets are distinguished by whether the merger was completed or not. P-values for difference of means tests between recommendation levels are also reported. Bolding indicates significance at the $10 \%$ level or better.

\begin{tabular}{lccrrrr}
\hline & Rec & N & 3-month & 6-month & 1-year & 2-year \\
\hline Acquirer & & & & & & \\
\hline All & $<2$ & 2459 & $-0.95 \%$ & $-2.67 \%$ & $\mathbf{- 8 . 1 5 \%}$ & $\mathbf{- 8 . 9 8 \%}$ \\
All & $\geq 2$ & 1582 & $0.42 \%$ & $0.85 \%$ & $\mathbf{2 . 0 4 \%}$ & $\mathbf{5 . 5 5 \%}$ \\
Difference & & & $1.37 \%$ & $3.52 \%$ & $10.19 \%$ & $14.53 \%$ \\
$p$-val & & & 0.1991 & $\mathbf{0 . 0 1 5 9}$ & $\mathbf{0 . 0 0 0 1}$ & $\mathbf{0 . 0 0 0 1}$ \\
Completion & $<2$ & 2106 & $-0.37 \%$ & $-2.09 \%$ & $\mathbf{- 7 . 7 3 \%}$ & $\mathbf{- 7 . 9 5 \%}$ \\
Completion & $\geq 2$ & 1344 & $0.36 \%$ & $1.09 \%$ & $\mathbf{2 . 1 9 \%}$ & $\mathbf{5 . 6 8 \%}$ \\
Difference & & & $0.73 \%$ & $3.18 \%$ & $9.92 \%$ & $13.63 \%$ \\
$p$-val & & & 0.4932 & $\mathbf{0 . 0 3 0 7}$ & $\mathbf{0 . 0 0 0 1}$ & $\mathbf{0 . 0 0 0 1}$ \\
Terminated & $<2$ & 353 & $-6.09 \%$ & $-7.75 \%$ & $\mathbf{- 1 1 . 8 5 \%}$ & $\mathbf{- 1 8 . 0 3 \%}$ \\
Terminated & $\geq 2$ & 138 & $1.05 \%$ & $-1.63 \%$ & $0.51 \%$ & $4.25 \%$ \\
Difference & & & $7.14 \%$ & $6.12 \%$ & $12.36 \%$ & $22.28 \%$ \\
$p$-val & & & $\mathbf{0 . 0 9 1 2}$ & 0.3163 & 0.1550 & $\mathbf{0 . 0 5 8 6}$ \\
\hline Target & & & & & & \\
\hline Terminated & $<2$ & 300 & $-2.04 \%$ & $6.05 \%$ & $4.35 \%$ & $10.75 \%$ \\
Terminated & $\geq 2$ & 160 & $-3.02 \%$ & $1.61 \%$ & $2.19 \%$ & $6.59 \%$ \\
Difference & & & $-0.98 \%$ & $-4.44 \%$ & $-2.16 \%$ & $-4.16 \%$ \\
$p$-val & & & 0.8922 & 0.6286 & 0.9363 & 0.9408 \\
\hline
\end{tabular}


Figure 1

\section{Distribution of Recommendation Revisions from Announcement through Resolution}

This figure shows the distribution of acquirer and target favorable and unfavorable recommendations from the merger announcement date through either completion or termination. Panel A shows the number of days that has passed from the merger announcement date relative to the percentage of total recommendations split by upgrade and downgrade for acquirers and targets by time bucket (i.e., $43.7 \%$ of all target downgrades occur within Days 0 to 5 from the merger announcement date). Panel B provides a normalized depiction using methodology in Malmendier, Opp, and Saidi (2012), where the merger horizon is normalized to our average of 130 days. Recommendation data is collected from $\mathrm{I} / \mathrm{B} / \mathrm{E} / \mathrm{S}$ and completion and termination dates are collected from SDC.

\section{Panel A: Recommendation Distribution}

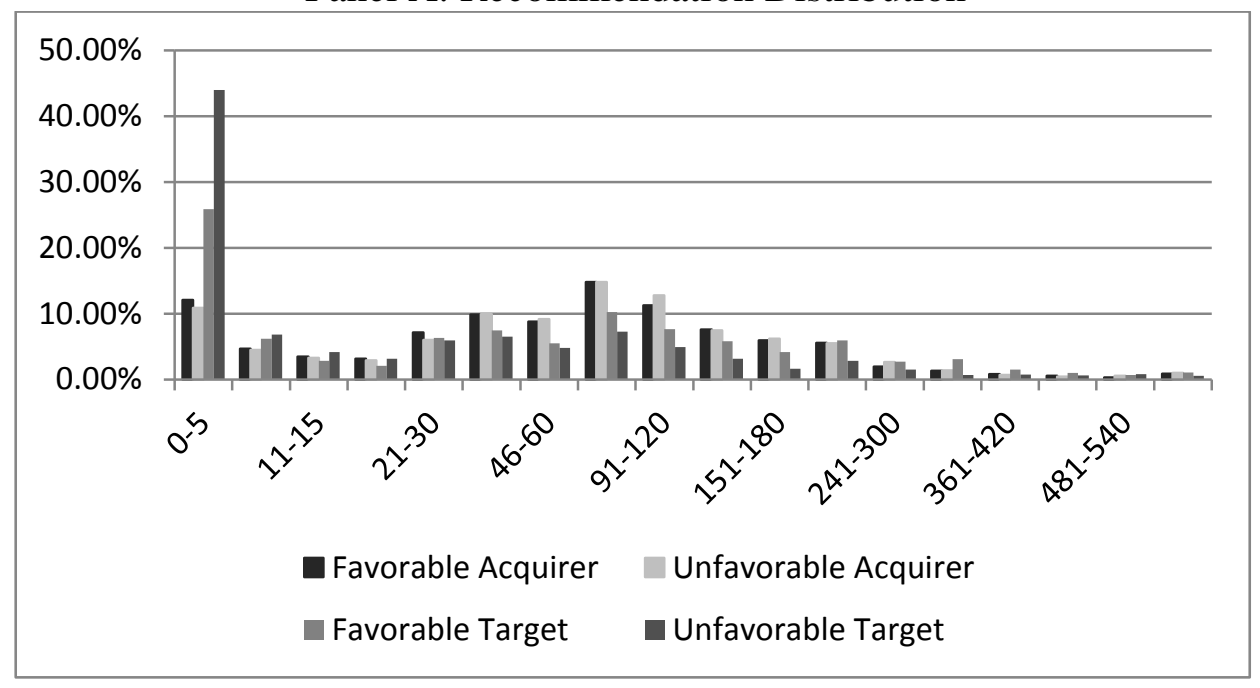

Panel B: Normalized Distribution

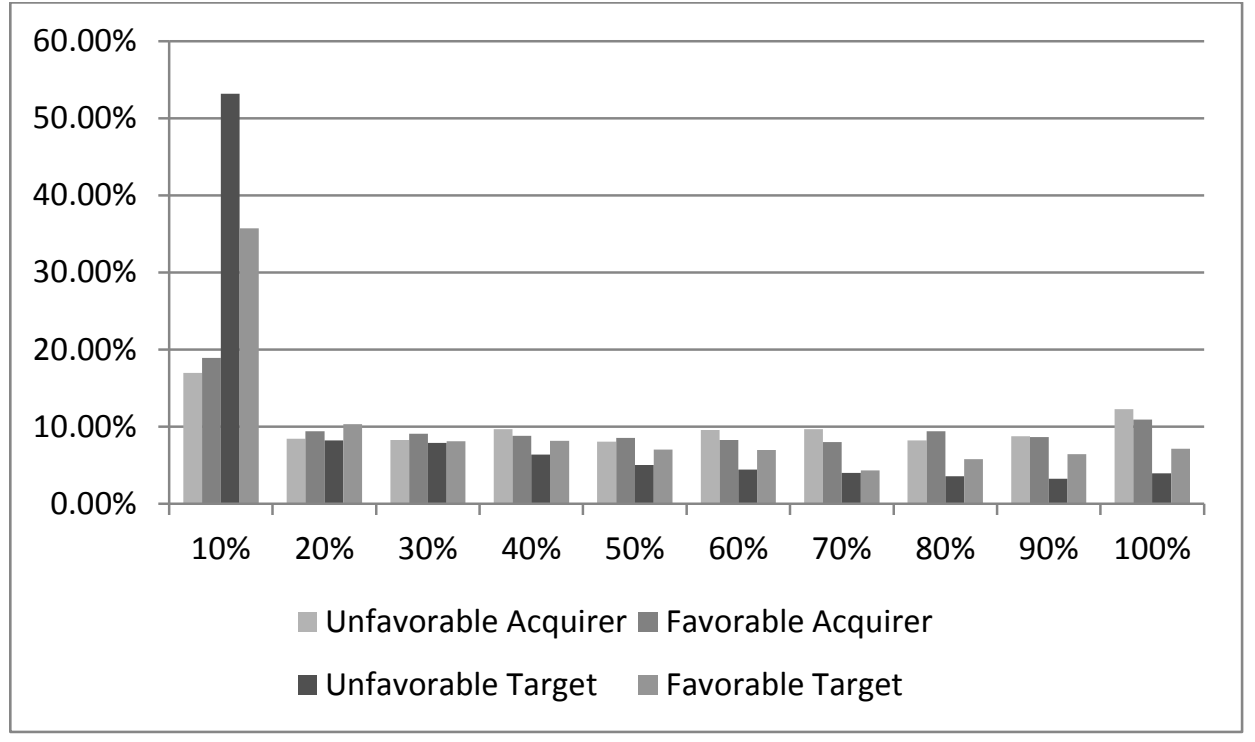

